\title{
ELEMENTAL MAPPING OF BONE STRONTIUM IN RATS TREATED WITH STRONTIUM RANELATE AND STRONTIUM CITRATE USING $2 D$ MICRO-XRF AND 3D DUAL ENERGY K-EDGE SUBTRACTION X-RAY IMAGING
}

\author{
by \\ Daniel Arturo Cardenas \\ Bachelor of Science \\ Ryerson University \\ 2015
}

\author{
A thesis \\ presented to Ryerson University \\ in partial fulfilment of the \\ requirements for the degree of \\ Master of Science \\ in \\ Biomedical Physics \\ Toronto, Ontario, Canada \\ @ Daniel Cardenas, 2017
}




\section{Author's Declaration}

I hereby declare that I am the sole author of this thesis. This is a true copy of the thesis, including any required final revisions, as accepted by my examiners.

I authorize Ryerson University to lend this thesis to other institutions or individuals for the purpose of scholarly research.

I further authorize Ryerson University to reproduce this thesis by photocopying or by other means, in total or in part, at the request of other institutions or individuals for the purpose of scholarly research.

I understand that my thesis may be made electronically available to the public.

Daniel A. Cardenas 


\section{Abstract}

ELEMENTAL MAPPING OF STRONTIUM IN RATS TREATED WITH STRONTIUM RANELATE AND

STRONTIUM CITRATE USING 2D MICRO-XRF AND 3D DUAL ENERGY K-EDGE SUBTRACTION

X-RAY IMAGING

Daniel A. Cardenas

Master of Science, 2017

Biomedical Physics

Department of Physics, Ryerson University

Strontium-based medications, such as strontium ranelate, have been shown to have therapeutic effects in the treatment of osteoporosis, other strontium salts are assumed to have similar effects on bone health. The objective of this study was to compare the distribution of strontium in animal bones following administration of strontium ranelate and strontium citrate. Humerus bones were collected from female Sprague-Dawley rats that were dosed daily over ten weeks with strontium ranelate and strontium citrate, and no strontium (control). Bones were imaged using 2D micro-XRF and 3D dual energy KES X-ray imaging. The 2D imaging revealed differences in strontium and calcium levels between samples from treated and non-treated animals $(p<0.001)$. 3D images obtained showed that strontium was observed to be largely present in the trabecular regions under the epiphyseal plate with concentrations of approximately 5 to $15 \mathrm{mg} / \mathrm{cm}^{3}$ in the bones of both strontium treated groups. The thickness of the strontium layers below the growth plate in both the strontium ranelate and strontium citrate sample were not significantly different $(p=0.9201)$. Both imaging studies performed in this work showed that strontium from 
both salts is heterogeneously distributed in newly formed bone during treatment. 


\section{Acknowledgements}

The collaboration and support from the many individuals I had the privilege to work with has made the pursuit of this degree rich and fulfilling. First, I would like to thank the team at the Atominstitut in Vienna, Austria, for their incredible level of assistance and support throughout the course of my experiments. Particularly, Anna and Mirjam who were always available to provide advice and assistance. I would also like to thank Dr. Christina Streli and Dr. Peter Wobrauschek for extending a warm welcome and allowing me to use their amazing facilities.

Next, I would like to thank Drs. David Cooper and Arash Panahifar for providing technical support and lending their knowledge to successfully complete the 3D imaging experiments at the Canadian Light Source (CLS) in Saskatoon. The spectacular strontium images could not have been produced without the expertise of Dr. Panahifar.

I would like to also thank Dr. David Fleming and Dr. James Gräfe for lending their expertise as my supervisory committee.

Finally, but definitely not least, I would like to wholeheartedly thank Dr. Ana PejovićMilić for her continual guidance and support through the last two years. Dr. PejovićMilić is an exemplary academic with an abundance of patience and willingness to help me succeed. She has been a great mentor for the past two years and I hope, for years to come. 
This thesis is dedicated to my Grandmother, who has always believed in me and encouraged me to achieve my academic goals. 


\section{Contents}

Author's Declaration $\quad$ ii

$\begin{array}{ll}\text { Abstract } & \text { iii }\end{array}$

$\begin{array}{ll}\text { Acknowledgements } & \text { v }\end{array}$

List of Symbols $\quad$ x

List of Abbreviations $\quad$ xi

List of Tables $\quad$ xii

List of Figures $\quad$ xiv

1 Introduction 1

1.1 Osteoporosis and Strontium in Bone . . . . . . . . . . . . . . . 1

1.1.1 Osteoporosis and Bone Health . . . . . . . . . . . . . . . 1

1.1.2 Strontium-based Treatment for Osteoporosis . . . . . . . . . . 3

1.1.3 Strontium Supplementation using other Strontium Salts . . . . . . 7

1.1.4 Bone Anatomy and Osteoporosis . . . . . . . . . . . . . . 8

1.2 Micro X-ray Fluorescence Imaging . . . . . . . . . . . . . . . . . 11

1.3 Dual Energy K-edge Subtraction Imaging . . . . . . . . . . . . . . . . . . . . . . . . . 15

1.4 Preceding Animal Study . . . . . . . . . . . . . . . 18

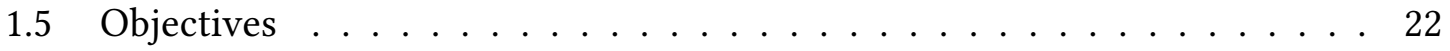

2 Strontium Distribution in Animal Bones 23

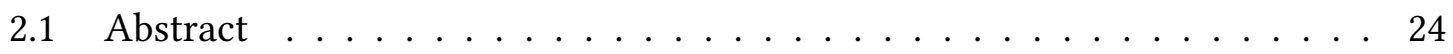

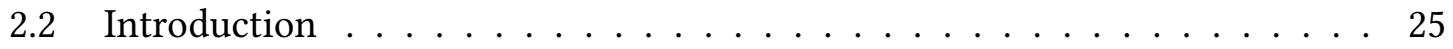

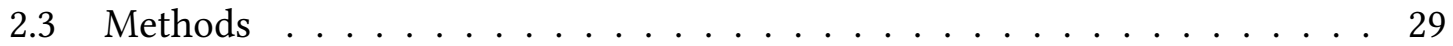

2.3.1 Animal Model . . . . . . . . . . . . . . . . . 29

2.3.2 Sample Preparation . . . . . . . . . . . . . . . 30

2.3.3 2D micro-XRF Elemental Strontium Mapping . . . . . . . . . . . 31

2.3.4 3D Dual Energy K-edge Subtraction X-ray Imaging . . . . . . . . . 33 


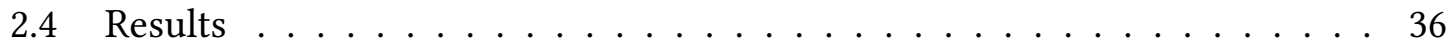

2.4 .12 D Elemental Strontium Images . . . . . . . . . . . . . 36

$2.4 .23 \mathrm{D}$ Elemental Strontium Images . . . . . . . . . . . . . . . . . . . . . . . . . .

2.5 Discussion . . . . . . . . . . . . . . . . 41

3 Conclusions and Future Work 49

3.1 Summary of the Study . . . . . . . . . . . . . . . . . 49

3.2 Future Work . . . . . . . . . . . . . . . . . . . 53

$\begin{array}{ll}\text { References } & 56\end{array}$ 


\section{List of Symbols}

$E_{A} \quad$ Energy 'above' the K-edge energy of an element (keV)

$E_{B} \quad$ Energy 'below' the K-edge energy of an element (keV)

$\mu_{A} \quad$ Linear attenuation coefficient of the 'above' energy $\left(\mathrm{cm}^{-1}\right)$

$\mu_{B} \quad$ Linear attenuation coefficient of the 'below' energy $\left(\mathrm{cm}^{-1}\right)$

$\mu_{A}(x, y) \quad$ Planar intensity map for 'above' energy

$\mu_{B}(x . y) \quad$ Planar intensity map for 'below' energy

$\rho_{C} \quad$ Mass density of contrast element $\left(\mathrm{g} / \mathrm{cm}^{3}\right)$

$\rho_{M} \quad$ Mass density of the material $\left(\mathrm{g} / \mathrm{cm}^{3}\right)$

$\frac{\mu}{\rho} \quad$ Mass attenuation coefficient $\left(\mathrm{cm}^{2} / \mathrm{g}\right)$

$\rho_{C}(x, y) \quad$ Density of the contrast element

$\rho_{M}(x, y) \quad$ Density of the material element

[Sr] Elemental strontium intensity (counts)

[Ca] Elemental calcium intensity (counts)

[Sr+Ca] Total intensity from strontium and calcium signals

\%Sr Percent strontium contribution to bone

$\% \mathrm{Ca} \quad$ Percent calcium contribution to bone 


\title{
List of Abbreviations
}

\author{
BMD Bone mineral density \\ BMIT-BM Biomedical Imaging and Therapy Bending Magnet \\ CLS Canadian Light Source \\ DXA Dual-energy X-ray absorptiometry \\ EMA European Medicines Agency \\ ICP-MS Inductively coupled plasma mass spectroscopy \\ KES K-edge subtraction imaging \\ $\mu \mathrm{CT} \quad$ Micro Computed Tomography \\ micro-XRF Micro X-ray Fluorescence \\ SOTI Osteoporosis Therapeutic Intervention \\ TROPOS TReatment Of Peripheral OSteoporosis
}




\section{List of Tables}

1.1 The daily elemental strontium dose for the treated groups. (Adapted from Wohl et al, 2013) . . . . . . . . . . . . . . . 22

2.1 Bone samples used for 2D micro-XRF and 3D dual energy KES imaging. . . 31

2.2 Percent calcium contribution \% Ca and percent strontium contribution $\% \mathrm{Sr}$ in bones supplemented with strontium ranelate and strontium citrate as well as no supplementation (control). The area of each selected region is given in pixels $\left(50 \times 50 \mu \mathrm{m}^{2} /\right.$ pixel $) \ldots \ldots \ldots \ldots$

2.3 Strontium layer thicknesses taken at three different spots under the epiphyseal plate for the samples shown in Figure $2.2 \ldots \ldots . \ldots$ 


\section{List of Figures}

1.1 Diagram depicting the three main areas of interest in the study; the diaphysis (shaft), metaphysis and epiphysis as well as the epiphyseal line (plate). This type of structure can be found in bones such as the humerus

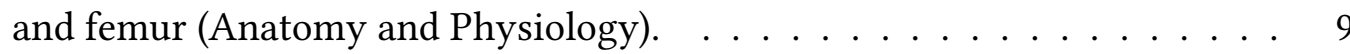

1.2 In-house micro-XRF system at the TU Wien Atominstitut in Vienna, Austria. The system counts with an Oxford Instruments 'Apogee' (Abingdon, Oxon, UK) low power microfocus X-ray tube with a $\mathrm{Rh}$ anode, maxium power $20 \mathrm{~W}$. The detector is a $30 \mathrm{~mm}^{2} \mathrm{Si}(\mathrm{Li})$ detector (UTW, Gresham, now e2v, Milpitas, CA, USA). The setup is housed in a custom vacuum chamber that also protects the user from radiation exposure (Smolek et al,

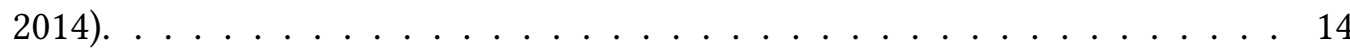

1.3 A graph of the mass attenuation coefficient $(\mu / \rho)$ vs photon energy $(\mathrm{MeV})$. The discontinuity at the K-edge of strontium $(16.105 \mathrm{keV})$ is demonstrated in the region between $10^{-2}$ and $10^{-1} \mathrm{MeV}$. Adopted from NIST (39). . . . . 16 
1.4 Computed tomography slice before flat-field correction (top); and after flat-field correction (bottom). The epiphyseal plate is clearly distinguishable, the translucent material at the base is the super glue used to fix the

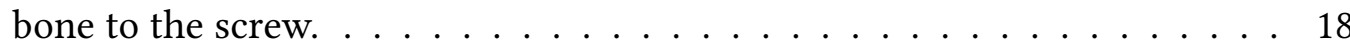

1.5 (a) Positioning of the rat hind limb during XRF measurements. The rat was anaesthetized and the tibia held horizontal during the measurement. (b) Position of the rat hind limb (in cross section) relative to the XRF detection system. (Adapted from Wohl et al, 2013). . . . . . . . . . . . . 20

2.1 2D elemental maps of calcium (Ca) and strontium ( $\mathrm{Sr}$ ) for, (a) strontium ranelate $(15 \times 43$ pixels $)$, and $(\mathbf{b})$ strontium citrate $(26 \times 55$ pixels $)$. Elemental maps are displayed in terms of absolute intensities. The images below the maps are electron light microscopy scans used to select the regions of interest (c) strontium ranelate, and (d) strontium citrate; regions scanned are indicated using a red frame. $\ldots \ldots \ldots \ldots \ldots \ldots$

2.2 Cross-sections of the 3D elemental strontium maps of rat bones treated with, (a) strontium ranelate, (b) strontium citrate, and (c) control (nontreated). Images (a) through (c) depict the epiphyseal plate within the head of each proximal humerus. . . . . . . . . . . . . . . . 39

2.3 An elemental strontium map of the medial (shaft) of one of the strontium

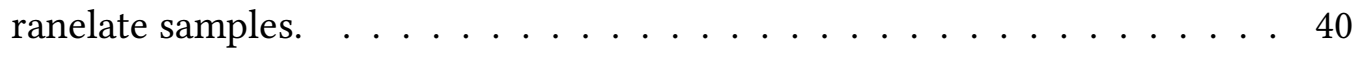




\section{Chapter 1}

\section{Introduction}

\subsection{Osteoporosis and Strontium in Bone}

\subsubsection{Osteoporosis and Bone Health}

Osteoporosis is a widespread issue that affects people around the globe. In the USA, the prevalence of osteoporosis is $10.3 \%$ in men and women aged 50 or over (Wright et al, 2014). Osteoporosis is thought to arise from the effects of various factors such as diet, environmental stressors, side effects from medications, and hormonal changes (Anne et al, 2014; Anjos et al 2004). Osteoporosis develops when an imbalance in the bone remodelling process occurs between the resorption and secretion phases during the bone turnover process (Anne et al, 2014). The hydroxyapatite crystal $\left[\mathrm{Ca}_{10}\left(\mathrm{PO}_{4}\right)_{6}(\mathrm{OH})_{2}\right]$ is the main component of calcified tissue and is the primary "receptor" for bone-seeking elements such as calcium and other common table II elements such as strontium and lead (Riedel et al, 2016). The 
bone remodelling and modelling process is a very complex mechanism that is essentially a balancing act between various processes. The imbalance occurs between the resorption of old bone; the breakdown of hydroxyapatite crystal by specialized cells called osteoclasts and the secretion of new crystal by the action of osteoblasts, bone-secreting specialized cells (Bonneyle et al 2008; Naylor and Eastell, 2012). Bone quality is dependent on many factors such as: mineral crystal size and shape, chemical composition, and crystal lattice arrangement ( $\mathrm{Li}$ et al, 2010). The magnitude of the issue is very evident and the need to improve and find suitable treatments for individuals suffering from osteoporosis is an ongoing area of research. Alleviating the symptoms of osteoporosis and reducing the risk of fractures is critical, as these can lead to disability or mortality (Misiorowski et al, 2017). A wide selection of treatments to combat the risk of fracture that results from loss of bone mineralization are available. Early treatments aimed at alleviating the symptoms of osteoporosis in men and women involve using calcium and vitamin D supplements which are essential for bone mineralization (Solomon et al, 2014; Hedge et al 2016). Today, the common antiresorptive treatments taken by patients are bisphosphonates, either orally or intravenously, and on occasion paired with other osteoporotic treatments (Liu et al, 2016). Other antiresorptive treatments include denosaub, calcitonin, raloxifene, and teriparatides (Hedge et al, 2016). More recent methods to stimulate bone growth have resulted in the development of parathyroid hormone (PTH) analogues; however, they are costly and may be linked to risk of developing cancer (Neer et al, 2001). The latest type of treatment is strontium-based medication, which has been shown to increase bone density 
and therefore reduce the risk of osteoporotic fractures due to the element's high atomic weight relative to calcium if incorporated into bone (Meunier et al, 2004; Seeman et al, 2004; Ammann et al 2007).

Despite the availability of potential treatments, many patients at risk of having fragility associated fractures, or who have already suffered one, do not undergo any treatment to treat their condition. This so called "osteoporosis treatment gap" is characterized by the fact that less than $20 \%$ of individuals who have already suffered fractures receive any osteoporotic treatment and the same is true for less than $10 \%$ of older women with fragility fractures (Kanis et al, 2014). In addition, studies report the gap is continually increasing over time (Kanis et al 2014, Lewiecki et al, 2017). Perhaps the widespread use of alternative strontium salts, such as strontium citrate, could help alleviate this concerning trend due their availability in health food stores without a prescription and lower relative cost.

\subsubsection{Strontium-based Treatment for Osteoporosis}

A method to remedy or improve the symptoms that are caused by osteoporosis would be to increase bone strength by affecting different factors of bone quality. One such method that has been used since the 1950s is to deliver elemental strontium to the bones of osteoporotic patients, an element who has many similar properties to the main component of calcified tissue, calcium (Tournis et al, 2006). Strontium $\left(\mathrm{Sr}^{2+}\right)$ is naturally occurring element in many types of vegetables, it is estimated that natural daily strontium uptake is approximately 2.0 to $4.0 \mathrm{mg}$ per day and can be found in human bone and tooth enamel 
in trace amounts (Tournis et al, 2006). The lack of strength in osteoporotic bones leads to elevated risks associated with the condition such as back pain, bad posture, and most commonly, fragility-associated fractures. The need to prevent bone fractures has led to the therapeutic use of bone seeking elements that can substitute for calcium in the hydroxyapatite of the bone. Strontium has been shown to possess strong bone seeking properties (Li et al, 2014). Many beneficial effects may be achieved at low doses, however, toxic effects at higher levels such as: enamel mottling may arise, rickets and osteomalacia; the proper amount of elemental strontium to be administered is crucial (Curzon and Spector, 1977).

The only current strontium-based medication used in the treatment of postmenopausal osteoporosis is strontium ranelate. If delivered in non-toxic amounts, strontium ranelate has continually been demonstrated to reduce the risk of osteoporotic fracture and improve bone quality during treatment in humans and animals (Amman et al 2004; Boivin et al, 2012; Komrakova et al, 2015). The reduction in fracture risk is achieved without significant changes to bone michroarchitecture and bone intrinsic qualities, while increasing bone mineral density (BMD) (Roschger et al, 2010; Siccardi et al, 2010; Querido et al, 2014; Mierzwa et al, 2017). The main mechanism of incorporation into the bone is through calcium substitution and ionic surface exchange on hydroxyapatite crystals (Riedel et al, 2016), where $50-80 \%$ of absorbed strontium is heterogeneously incorporated in areas of active bone remodeling during treatment (Oliveira et al, 2012). It is reported that approximately $5 \%(0.5: 10)$ to $10 \%(1: 10)$ of calcium atoms are replaced or substituted by strontium 
(Li et al, 2009; Pemmer et al 2013; Tournis et al, 2006; Doublier et al, 2011). Strontium ranelate is able to provide these health benefits through a dual mode of action (Reginster et al, 2006). This 'mechanism' works by suppressing the breakdown of old bone and promoting the formation of new hydroxyapatite during the bone turnover process. It is claimed that strontium ranelate can achieve these results by influencing the activities of specialized cells, known as osteoblasts, responsible for secreting new bone material and osteoclasts, which breakdown and absorb old bone (Bonneyle et al, 2007; Almeida et al 2016). Trace amounts of evenly distributed strontium from normal dietary habits may be present in older bone formed before commencement of therapeutic treatment via strontium treatment (Zamburlini et al, 2008; Thurber et al, 1958; Hodges et al, 1950). In contrast, studies have shown that bone formed during strontium ranelate treatment have heterogeneous distributions of elemental strontium with high concentrations found particularly in trabecular bone of monkeys, goats and rats (Oliveira et al, 2012). This trend is also reflected in postmenopausal women receiving strontium ranelate to treat their osteoporotic symptoms (Boivin et al, 2012). Therefore it can be concluded that elemental strontium is heterogeneously deposited in trabecular bone over cortical bone regardless of the organism receiving additional strontium (Wu et al, 2012).

Previous studies have reported a plateau in strontium content after three years of treatment in postmenopausal women suggesting that elemental strontium does not build up in calcified tissues after a certain concentration has been reached (Boivin et al, 2009). However, this trend was not corroborated by the in vivo XRF study of rats where strontium 
content continued to increase after ten weeks of strontium administration suggesting a linear increase in strontium levels (Wohl et al, 2013). Strontium distribution can be dependent on a variety factors such as age and sex of the person, concentration in the blood, duration of treatment, type of strontium salt utilized and age of the bone (Tournis et al, 2006). Further analysis is required to fully characterize the accumulation and distribution of strontium. One way of approaching this would be by using non-destructive methods such as micro-XRF techniques and synchrotron radiation that can be used to image and map elemental strontium in bone.

Much like other medications, potential side effects may arise while taking a certain treatment. While health benefits of strontium ranelate have been continually touted for last decade, in 2012 concerns that the use of strontium ranelate was linked to increased cardiovascular risk (Reginster, 2014). Strontium ranelate was registered in 2004 for use in the treatment of postmenopausal osteoporosis; however, in 2013 the European Medicines Agency (EMA) published data suggesting that the medication increased the risk of myocardial infarction (Bolland et al, 2016). Various studies conducted into the potential risks associated with cardiac health have demonstrated that strontium ranelate increases the risk of non-fatal myocardial infarction and significantly higher risk of death from cardiovascular events (Abrahamsen et al, 2014; EMA, 2014). Atteritano and colleagues concluded that treatment with this drug did not change the cardiovascular risk in osteoporotic women; however, this study only looked at individuals treated over twelve (12) months (Atteritano et al, 2016). Despite the evidence for potential cardiac health concerns, the 
EMA concluded that the benefits of strontium ranelate outweigh its risks (EMA, 2014). As a result, this particular strontium medication is still prescribed to patients suffering from osteoporosis, but with contraindications to patients with a history of hypertension (Reginster, 2014). Whether similar risks are associated with other strontium supplements remains to be seen.

\subsubsection{Strontium Supplementation using other Strontium Salts}

The literature on the health benefits of strontium ranelate as a medication is extensive and supports the dual mode of action theory, however, little research has been published on alternative strontium salts that may provide similar health benefits and are more readily available in North America. Alternative strontium salts include strontium citrate $\left(\mathrm{C}_{12} \mathrm{H}_{14} \mathrm{O}_{14} \mathrm{Sr}\right)$, strontium chloride $\left(\mathrm{SrCl}_{2}\right)$, strontium carbonate $\left(\mathrm{SrCO}_{3}\right)$, strontium lactate $\left(\mathrm{C}_{6} \mathrm{H}_{10} \mathrm{O}_{6} \mathrm{Sr}\right)$, and strontium gluconate $\left(\mathrm{C}_{6} \mathrm{H}_{12} \mathrm{O}_{7} \mathrm{Sr}\right)$. The aforementioned strontium salts are in use as natural health food products in Canada (Ministry of Health, 2015) without the need of a prescription. One of these readily available strontium salts is strontium citrate, which is the strontium supplement that will be compared to strontium ranelate in this work. Early attempts to look into other strontium salts such as strontium lactate were published as early as 1952 in a paper by (Shorr and Carter, 1952) however, a lack of active research into alternative salts has resulted into a gap in the literature of several decades (Zamburlini et al, 2008). Elemental strontium distribution in bone delivered by strontium citrate has been the primary focus of our group as we attempt to further expand the 
knowledge on the health benefits of alternative salts (Moise et al, 2012; Wohl et al, 2013; Moise et al, 2016). One such study is the work preceding this one, and will be discussed at length in Section 1.4. A study performed on skeletally mature rabbits demonstrated that new bone formation was effectively accelerated by strontium citrate administration at a daily dose of $675 \mathrm{mg} / \mathrm{kg} /$ day (Taylor et al, 2017). Pemmer and colleagues published a micro-XRF study on the uptake of strontium in bones of ovariectomized (OVX) rats where strontium was predominantly found in newly formed bone from both strontium ranelate and strontium chloride treated animals (Pemmer et al, 2011). In addition, they reported that strontium incorporation in $\mathrm{SrCl}_{2}$ treated animals was lower than the strontium ranelate treated animals (Pemmer et al, 2011). Today, we continue to lack concrete literature on the effects of strontium salts in treating postmenopausal osteoporosis. The need to fill this gap is evident, and it is the goal of this study to further encourage research into alternative strontium salts by showing the distribution of strontium in the rat bones delivered by two strontium salts is similar.

\subsubsection{Bone Anatomy and Osteoporosis}

The skeleton of an adult human contains a total of 213 bones; the appendicular system comprises 126 of the bones in the skeleton and supports the appendages of the body. Bones are divided into four main groups; long bones, short bones, flat bones, and irregular bones. Calcified structures found in the long bone group are primarily tasked with supporting the weight and movement of the body; examples of these bones are the femur, 


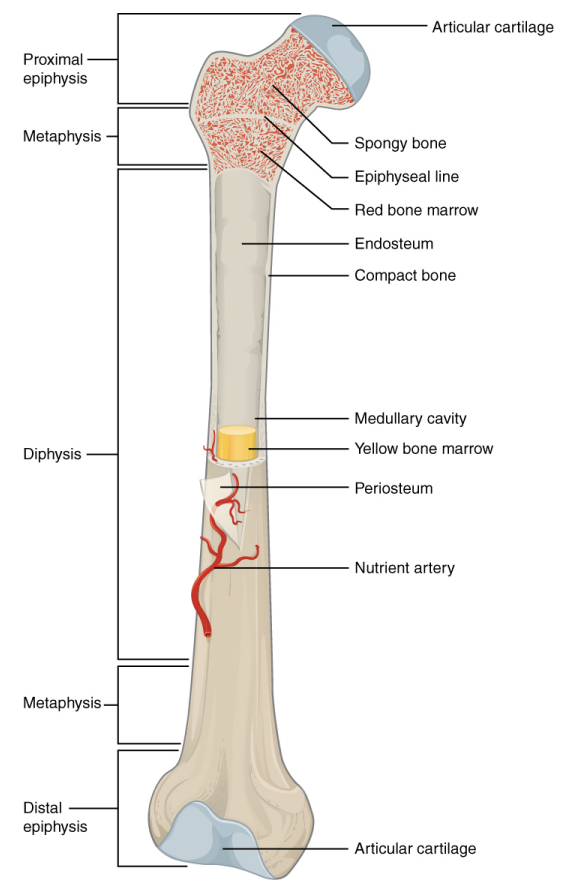

Figure 1.1: Diagram depicting the three main areas of interest in the study; the diaphysis (shaft), metaphysis and epiphysis as well as the epiphyseal line (plate). This type of structure can be found in bones such as the humerus and femur (Anatomy and Physiology).

humerus and ulna among others. In addition to structural support and movement, the skeleton also serves a variety of additional functions such as protection of internal organs and maintenance of mineral homeostasis (Clarke, 2008). Therefore, the need to maintain proper bone health is evident for a good quality of life. Long bones are composed of a hollow shaft called the diaphysis. Inside the shaft a growth plate is present where the flared and cone-shaped structure beneath is known as the metaphysis and the rounded smooth structure above growth plate is called the epiphysis. The diaphysis is composed of dense cortical bone while the epiphysis and metaphysis are composed of a spongy network of trabecular bone. Cortical bone is dense and solid, while trabecular bone is reminiscent of a honeycomb like net of trabecular cones and rods (Clarke, 2008). The human skeleton is 
composed of $80 \%$ cortical and $20 \%$ trabecular bone on average (Clarke, 2008).

The formation of bone is a process of constant modeling and remodeling dependent on age, general health and lifestyle. Bone remodeling is essential in maintaining bone strength and mineral homeostasis by renewing old, worn tissue, and is essentially the same process in both cortical and trabecular structures. The turnover rate of trabecular bone is also necessary for the same purpose, however, the rate in trabecular bone is typically higher than the cortical bone turnover due to the fact that trabecular bone is more actively involved in other essential processes. Bone undergoes longitudinal and radial growth. Longitudinal growth occurs at the epiphyseal plate or more commonly known as the growth plate, here cartilage is formed in the metaphyseal and epiphyseal areas of long bones where it is subsequently converted into calcified tissue. Bone modeling and remodeling can be affected by a variety of factors, the disruption of the delicate balance in these processes can lead to significant consequences, osteoporosis being one of the most significant bone degenerative diseases that result from the imbalance of bone turnover processes.

Bone degenerating diseases continue to be a primary concern for aging populations in Canada and the US. In 2009, approximately 1.5 million Canadians over 40 years of age were estimated to have osteoporosis (Public Health Agency of Canada, 2009). The proportion of people who suffer from this disease can cause significant economical strains, such as in Europe where it is estimated that $€ 37.4$ billion was spent on treating bone fractures in 2010 alone (Kanis et al, 2013). Bone quality is dependent on many factors such as, mineral 
crystal size and shape, chemical composition, and crystal lattice arrangement (Li et al, 2010).

\subsection{Micro X-ray Fluorescence Imaging}

X-ray based techniques use basic physics principles for elemental analysis and characterization of materials and has been the method of choice for such purposes for many applications. More specifically, X-ray fluorescence (XRF) is a phenomenon that is widely used to analyze samples for the purpose of identifying chemical composition and offers unique advantages over other techniques. X-ray fluorescence is the process by which characteristic radiation is emitted from the atom of an element due to externally induced electronic transitions. This occurs when incident (primary) photons in the X-ray or gamma-ray range interact with the inner electrons of an atom. If the energy of this primary radiation is sufficient enough to overcome the binding energy of an energy state, then the electrons will be removed from their energy state leaving behind a 'hole' that needs to be filled. This change in atomic arrangement causes an unstable atomic structure; therefore, electrons from higher energy states drop down to fill the vacancy. This drop causes the atom to return to an energetically favourable state and results in the emission of secondary photon with energy equal to the difference in energy between the excited and ground state. The secondary photons are known as fluorescence or characteristic radiation due to the fact that every element has a unique atomic configuration and therefore electronic transitions will produce photons with unique wavelengths specific to the element. It is this phe- 
nomenon of characteristic fluorescent radiation that lends the XRF method its flexibility in many different applications.

Micro X-ray fluorescence spectroscopy (micro-XRF) is an analytical technique that is based on the basic principles of X-ray fluorescence that provides information about elemental concentration and also allows for mapping of the elemental distribution about the sample surface (Chinchon-Paya, 2015). Other analytical techniques such as Inductive Coupled Plasma Mass Spectrometry (ICP-MS) and Scanning Electron Microscope coupled to Energy Dispersive Spectrometry (SEM-EDS) can also be used to obtain the elemental make-up of a material at similar surface depths such as $(1-5 \mu \mathrm{m})$ in ICP-MS, however, resolution is greater in micro-XRF (Cordes et al, 2014; Ramos et al 2016). Micro-XRF also induces electronic triggering to obtain the characteristic fluorescence peaks for each element or material and allows for analysis of subsurface depth by using a polycapillary to focus the primary beam (Cordes et al, 2014; Chinchon-Paya, 2015). Thus the fundamental difference between the two techniques is the use of X-ray optics in micro-XRF that uses the polycapillary to restrict the X-ray source spot size to approximately $20-100 \mu \mathrm{m}$ (Cordes et al, 2014). The difference can be quite significant, a few hundred micrometres to a few millimetres compared to resolutions of just a few micrometres in micro-XRF (Smolek et al, 2014). The resolution of micro-XRF usually varies according to many factors such as the type of system used for measurements, energy of the excitation source, and the physical properties of the sample being analyzed. Micro-XRF can be used to image areas of approximately $100 \times 100 \mu \mathrm{m}^{2}$ down to areas with ranges of $10 \times 10 \mu \mathrm{m}^{2}$ depending on the 
individual set-up and polycapillary used. In addition to enhanced resolution, this method of x-ray fluorescence offers increased sensitivity and both are improved if coupled with synchrotron radiation (Lima et al, 2008). Synchrotron radiation micro-XRF is the latest trend where a lot of research is currently being conducted, it can provide a broader range of X-ray energies for excitation of a sample, as well as increased lateral resolution in order to produce 3D maps (Garrevoet et al, 2015). However, long scanning time and spectra analysis as well as beam time allocation continue to be significant limiting factors in the widespread use of synchrotron radiation micro-XRF. Therefore, custom and commercial benchtop micro-XRF systems continue to offer versatility for researchers. Micro X-ray fluorescence spectroscopy imaging can be used to analyze many different samples including biological tissues that require non-destructive methods such as hair, teeth enamel, and most prominently, bone (Cheung et al, 2016).

The micro-XRF method highlighted in this section is the first imaging method performed on the rat bone samples in this work. Measurements to produce 2D maps of strontium distribution and concentration on thin-sliced samples, one from each treatment group, are performed using the in-house custom-built micro-XRF system at the Atominstitut (Institute for Atomic and Subatomic Physics) in Vienna, Austria as depicted in Figure 1.2. The entire system is housed in a chamber that allows for the creation of a vacuum and aids in shielding the user and surrounding areas from radiation (Smolek et al, 2014). 


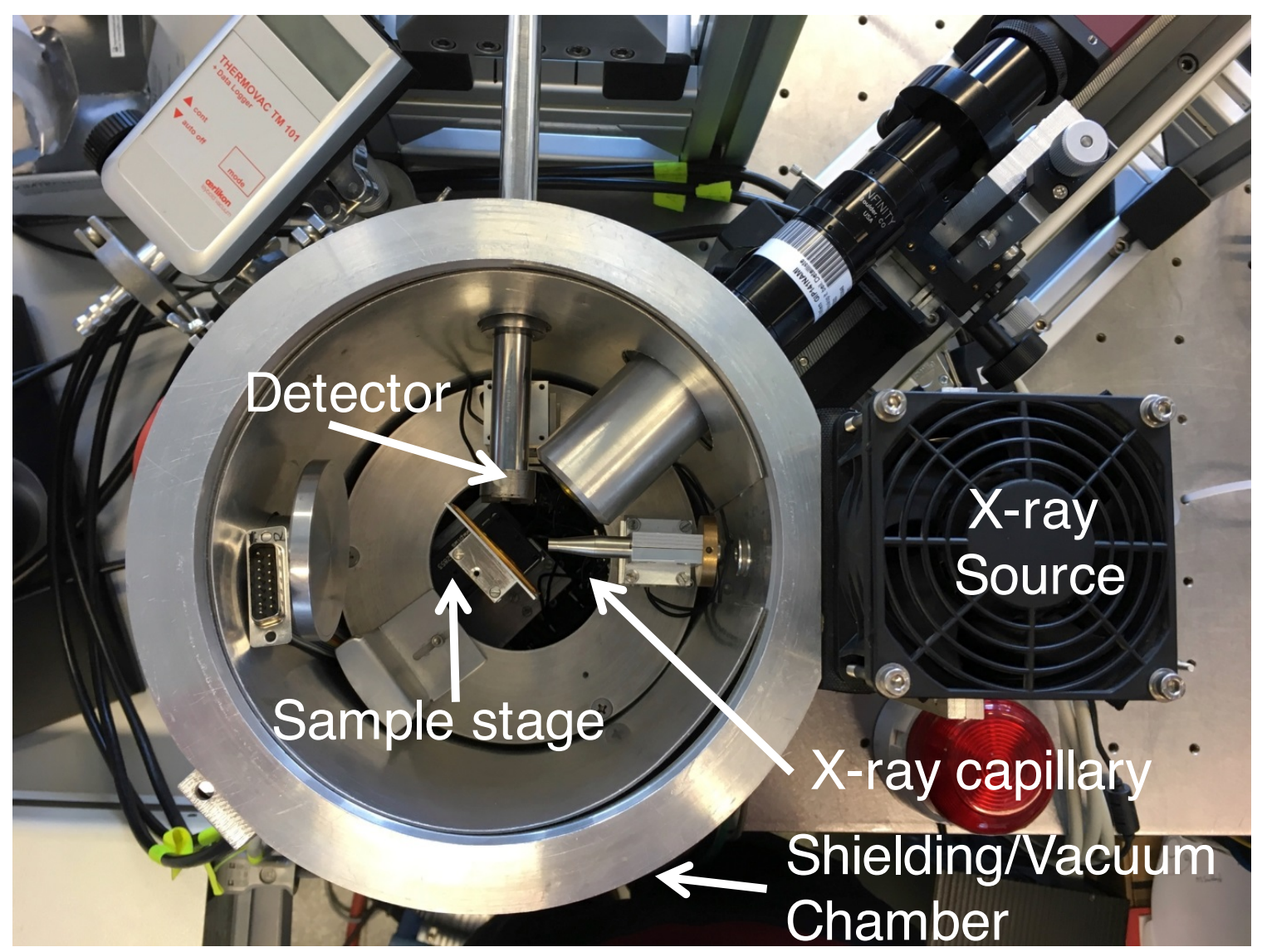

Figure 1.2: In-house micro-XRF system at the TU Wien Atominstitut in Vienna, Austria. The system counts with an Oxford Instruments 'Apogee' (Abingdon, Oxon, UK) low power microfocus $\mathrm{X}$-ray tube with a $\mathrm{Rh}$ anode, maxium power $20 \mathrm{~W}$. The detector is a 30 $\mathrm{mm}^{2} \mathrm{Si}(\mathrm{Li})$ detector (UTW, Gresham, now e2v, Milpitas, CA, USA). The setup is housed in a custom vacuum chamber that also protects the user from radiation exposure (Smolek et al, 2014). 


\subsection{Dual Energy K-edge Subtraction Imaging}

Another technique that exploits the properties of X-ray's interaction with matter to identify the composition of a material is known as Dual Energy K-edge Subtraction (KES) X-ray imaging. Different materials have unique linear attenuation coefficients $(\mu)$ that can allow differentiation between tissues. The linear attenuation coefficient of a material dictates the fraction of incident photons that will be absorbed as they travel through the medium; conversely, this parameter gives the number of photons transmitted through the medium and is heavily dependent on the energy of the radiation. These properties are very advantageous for medical diagnostic applications as well as research into trace element analysis. X-ray based techniques have been previously used to differentiate between mineralized and soft tissues such as dual energy photon absorptiometry (DPA) and dual energy X-ray absorptiometry (DXA).

However, previous techniques do not allow for single element differentiation offered by the fine-tuning of X-ray energies available using synchrotron radiation in the KES method, which allows for accurate 3D maps of a single element of interest (Kruger et al, 1977a; Cooper et al, 2012; Panahifar et al, 2016). This method exploits the discontinuity in linear attenuation coefficient that occurs at the 'K-edge' of an element, a region of interaction where the binding energy of the electrons in the K-shell of a particular element is the highest, after this 'boundary' has been reached, the linear attenuation coefficient drops significantly and steadily increases once again. In this study, we are producing elemental maps of strontium whose K-edge energy is $16.105 \mathrm{keV}$ (Figure 1.3). Imaging 


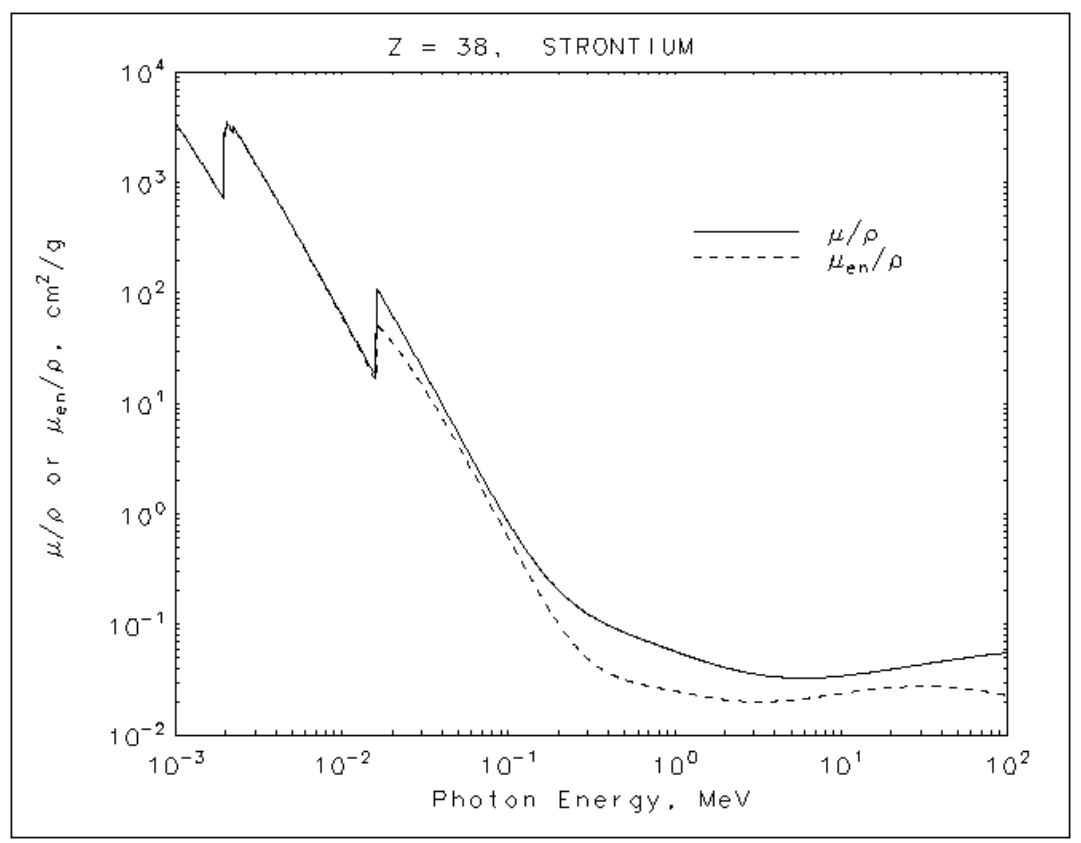

Figure 1.3: A graph of the mass attenuation coefficient $(\mu / \rho)$ vs photon energy $(\mathrm{MeV})$. The discontinuity at the K-edge of strontium $(16.105 \mathrm{keV})$ is demonstrated in the region between $10^{-2}$ and $10^{-1} \mathrm{MeV}$. Adopted from NIST (39).

a target at an energy slightly below and slightly above the K-shell binding energy of an element will result in contrast enhancement in the signals and results in two sets of images that can be subtracted to create the maps. The KES method can be used in projection or tomographic mode. Computed tomography reconstruction takes X-ray transmission line projections made at different angles and yields a planar linear attenuation map, $\mu(x, y)$. The object material and contrast elements under analysis can be described in dual energy KES computed tomography simply by their density, $\rho_{M}$ and $\rho_{C}$, respectively. Therefore, a 
linear planar map of any given object material and contrast element can be described by,

$$
\begin{aligned}
\rho_{C}(x, y)= & \frac{\frac{\mu\left(E_{B}\right)}{\rho_{M}} \mu_{A}(x, y)-\frac{\mu\left(E_{A}\right)}{\rho_{M}} \mu_{B}(x, y)}{\frac{\mu\left(E_{B}\right)}{\rho_{M}} \frac{\mu\left(E_{A}\right)}{\rho_{C}}-\frac{\mu\left(E_{A}\right)}{\rho_{M}} \frac{\mu\left(E_{B}\right)}{\rho_{C}}} \\
\rho_{M}(x, y)= & \frac{\frac{\mu\left(E_{A}\right)}{\rho_{C}} \mu_{B}(x, y)-\frac{\mu\left(E_{B}\right)}{\rho_{C}} \mu_{A}(x, y)}{\frac{\mu\left(E_{B}\right)}{\rho_{M}} \frac{\mu\left(E_{A}\right)}{\rho_{C}}-\frac{\mu\left(E_{A}\right)}{\rho_{M}} \frac{\mu\left(E_{B}\right)}{\rho_{C}}}
\end{aligned}
$$

where $\mu / \rho_{M}$ and $\mu / \rho_{C}$ are the mass attenuation coefficients of the object material and contrast element of the same energy, $E_{A}$ and $E_{B}$ are the 'above' and 'below' energies used to image before and after the K-edge energy of strontium. A detailed derivation of the planar map expression can be found in Cooper et al, 2012.

In the process of generating KES images, reconstruction and deconvolution of the tomographic images is required. In order to perform these corrections it is necessary to include flat-field and dark-field scans in the process. Flat-field images consist of taking images of the field-of-view with the beam turned on, without the bone sample in the frame. Dark-field images consist of radiographs taken with no photons (from the source) incident on the detector. Both types of images are used to correct for non-uniform background signals in the tomographic images of the bone samples (Weitkamp et al, 2011). The improvement in the quality of the sample images is apparent in Figure 1.4. 


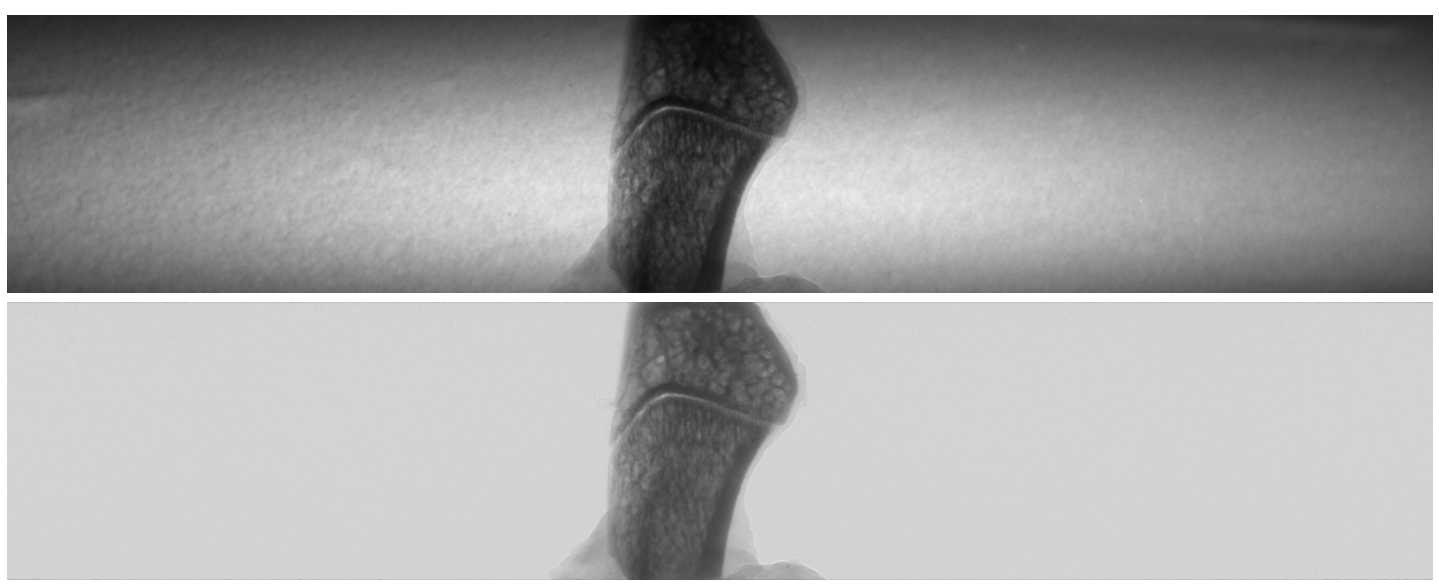

Figure 1.4: Computed tomography slice before flat-field correction (top); and after flatfield correction (bottom). The epiphyseal plate is clearly distinguishable, the translucent material at the base is the super glue used to fix the bone to the screw.

\subsection{Preceding Animal Study}

The distribution of elemental strontium in bone due to different strontium salts is still an active area of research that is still lacks extensive study. The bone samples analyzed in this work are obtained from the preceding study conducted by our group. The study by Wohl and colleagues aimed to expand the knowledge on the use of alternative strontium salts by comparing the levels of elemental strontium accumulated in the bones of rats treated with strontium ranelate and strontium citrate using in vivo X-ray fluorescence spectroscopy.

A vehicle-controlled animal study with the primary goal of comparing bone strontium concentrations in vivo over a period of ten weeks and ex vivo once animals are sacrificed in rat bones treated with strontium ranelate (SV Chembiotech inc. Edmonton, $\mathrm{AB}$ ) and strontium citrate (Dr. Paul Lohmann GmbH HG, Emmenthal, Germany) was reported in 2013 (Wohl et, 2013). Nineteen $(N=19)$ Sprague-Dawley (non-ovariectomized) female rats obtained at the time of acquisition, were skeletally mature twelve week-old animals. 
The animals were allowed to age in the lab in order to acclimatize to their new environment for a period of six weeks. The 18 week-old rats were then separated into three treatment groups; $(n=6)$ were assigned to receive strontium ranelate, $(n=7)$ were to receive strontium citrate, and $(n=6)$ were left as the 'control' group receiving a normal diet. Dosage was done daily at the same time of the day by administering the strontium salts using a strawberry flavoured gelatin in order to prevent competitive binding in the gut between strontium and calcium. The dosage of strontium ranelate was $625 \mathrm{mg} / \mathrm{kg} / \mathrm{day}$ and of strontium citrate was $676 \mathrm{mg} / \mathrm{kg} /$ day in order to deliver $213 \mathrm{mg} / \mathrm{kg} /$ day of elemental strontium, rats were dosed over a period of ten weeks.

Until this study, in vivo XRF techniques had only been used on human subjects and not on animals. ${ }^{125} \mathrm{I}$ brachytherapy seeds with initial activity of $13 \mathrm{MBq} /$ seed were inserted in a tungsten collimator and used as the excitation source (Protaseed, Core Oncology); X-ray fluorescence was measured with $\mathrm{Si}(\mathrm{Li})$ detector $(\mathrm{EG}+\mathrm{C}$, ORTEC). Calibration of the system was performed before any measurement was carried out on the live animals by using a cylindrical phantom (mimicking a human finger) contain 119.4 ppm Sr:Ca ratio. Measurements were done on the antero-medial aspect of the proximal tibia 4 and 8 weeks into administration of the strontium salts with a deadtime of 30-32\% per 900 s reading (Figure 1.5). Bone strontium levels were calculated by normalizing the strontium $\mathrm{K}_{\alpha}$ peak counts to the ${ }^{125}$ I coherent peak counts. After conclusion of the study, the rats were sacrificed and post-mortem XRF measurements were also performed. Inductively coupled plasma mass spectroscopy (ICP-MS) was employed to determine bone strontium content; three whole 
A

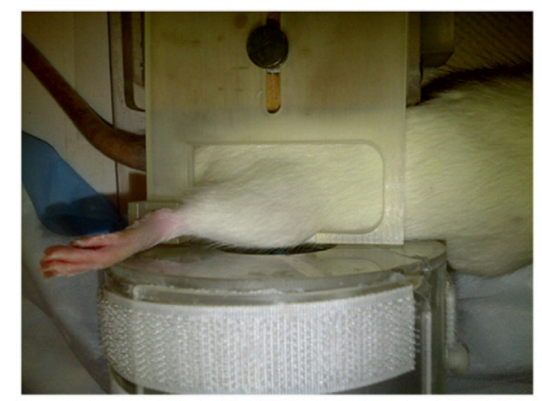

B

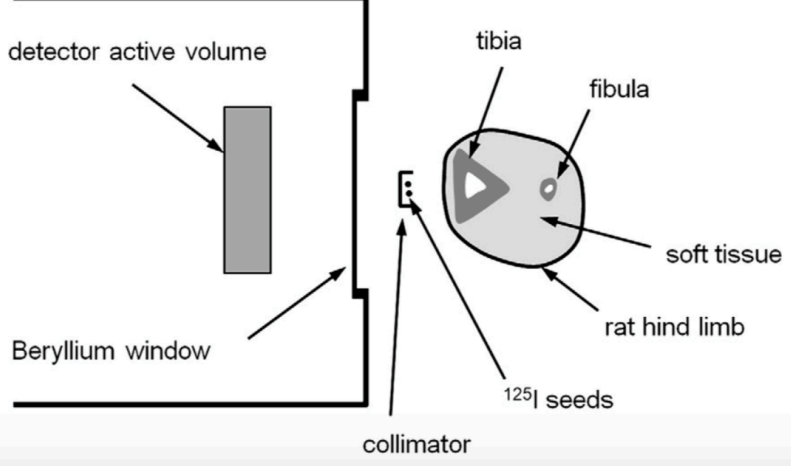

Figure 1.5: (a) Positioning of the rat hind limb during XRF measurements. The rat was anaesthetized and the tibia held horizontal during the measurement. (b) Position of the rat hind limb (in cross section) relative to the XRF detection system. (Adapted from Wohl et al, 2013).

tibias were dried and ashed in a muffle furnace at $700^{\circ} \mathrm{C}$, and further chemical ashing by acid digestion $\left(4 \% \mathrm{HNO}_{3}, 1 \% \mathrm{HClO}_{3}\right)$ at $150^{\circ} \mathrm{C}$ for 35 minutes. Finally, EDS microanalysis was performed on both strontium drugs in order to confirm their true strontium concentration.

The in vivo measurements done at 4 weeks and 8 weeks after the commencement of administration of strontium salts showed significant differences between the strontium ranelate and strontium citrate groups. The strontium citrate group showed $47 \%$ and $49 \%$ greater normalized bone strontium content at four (4) and eight (8) weeks, respectively, as compared to the strontium ranelate group. This difference can be attributed to the 
fact that the strontium citrate salt was actually delivering $35 \%$ more elemental strontium on a daily basis. As mentioned previously, the intended elemental strontium dose from both salts was $213 \mathrm{mg} / \mathrm{kg} /$ day, however, EDS analysis showed that the strontium citrate powder had $34.9 \%$ strontium content and strontium ranelate had $27.9 \%$ strontium content. Therefore, from the daily dosage of each salt it was determined that the actual amount of elemental strontium being delivered to the rats was $235.7 \mathrm{mg} / \mathrm{kg} /$ day (strontium citrate) and $174.3 \mathrm{mg} / \mathrm{kg} /$ day (strontium ranelate) as shown in Table 1. ICP-MS measurements of the ashed tibias collected from the treatment groups found that there was a statistically significant difference in strontium content between the treated and control groups, but no statistically significant difference in strontium levels between the two strontium treated groups. The difference in strontium content is corroborated by the ICP-MS data where the $\mathrm{Sr} / \mathrm{Sr}+\mathrm{Ca}$ ratio in strontium citrate group is $32.7 \%$ greater than the strontium ranelate group. The post-mortem strontium $K_{\alpha}$ signals were highly correlated with the in vivo data $\left(R^{2}=0.879, p<0.001\right)$ and were 3.1 times greater than the in vivo measurements, demonstrating that soft tissue attenuates the strontium signal from the bone. The study concluded that in vivo XRF techniques can be used to successfully measure bone strontium content in rats and more significantly, that strontium ranelate and strontium citrate are similarly effective in delivering elemental strontium to the bones of rats. Further detailed description of the study and discussion can be found in the corresponding publication, Wohl et al, 2013. 
Table 1.1: The daily elemental strontium dose for the treated groups. (Adapted from Wohl et al, 2013)

\begin{tabular}{l|cccc}
\hline $\begin{array}{l}\text { Drug } \\
\text { Administered }\end{array}$ & $\begin{array}{c}\text { Molecular } \\
\text { Formula }\end{array}$ & $\begin{array}{c}\text { Dose } \\
(\mathrm{mg} / \mathrm{kg} / \mathrm{day})\end{array}$ & $\begin{array}{c}\text { Calculated Sr Dose } \\
(\mathrm{mg} / \mathrm{kg} / \mathrm{day})\end{array}$ & $\begin{array}{c}\text { Actual Sr Dose } \\
(\mathrm{mg} / \mathrm{kg} / \mathrm{day})\end{array}$ \\
\hline Sr Ranelate & $\mathrm{C}_{12} \mathrm{H}_{6} \mathrm{~N}_{2} \mathrm{O}_{8} \mathrm{SSr}_{2}$ & 625 & 213 & 174.3 \\
Sr Citrate & $\mathrm{C}_{6} \mathrm{H}_{6} \mathrm{O}_{7} \mathrm{Sr}$ & 676 & 213 & 235.7 \\
\hline
\end{tabular}

\subsection{Objectives}

The in vivo study was conceived to compare the efficacy of two strontium salts in delivering elemental strontium to the bones of the animals treated with strontium ranelate (625 $\mathrm{mg} / \mathrm{kg} /$ day) and strontium citrate $(676 \mathrm{mg} / \mathrm{kg} /$ day).The study concluded that both salts, strontium ranelate and strontium citrate, were equally effective in delivering elemental strontium to the animal bones over the 10 -week period of administration. The purpose of this work is to further the findings of the Wohl and colleagues. To this end, existing X-ray fluorescence techniques were employed to obtain 2D and 3D elemental maps of strontium accumulated in the first forelimb (humerus) of the rats that provide quantitative and spatial information on the distribution of strontium in the rat bones that were frozen after the conclusion of the previous study. It was hypothesized that differences in the distribution of elemental strontium in treated rat bones is not attributable to the type of strontium salt used in the supplementation of the animals. 


\section{Chapter 2}

\section{Strontium Distribution in Animal}

\section{Bones}

Working paper for submission to the Journal of Bone and Mineral Research. Daniel A. Cardenas,

Anna Turyanskaya, Mirjam Rauwolf, Arash Panahifar, David Cooper, Gregory R. Wohl,

Christina Streli, Peter Wobrauschek and Ana Pejović-Milić. "Elemental Mapping of Stron-

tium in Rat Bones treated with Strontium Ranelate and Strontium Citrate using 2D micro-XRF

and 3D Dual Energy K-edge Subtraction X-ray Imaging”

Daniel Cardenas performed the experiments, analyzed the data, and drafted the manuscript. Anna Turyanskaya and Mirjam Rauwolf assisted with 2D micro-XRF data analysis and acquisition. Arash Panahifar performed the deconvolution and reconstruction of the 3D KES images. Christina Streli, Peter Wobrauschek, David Cooper and Gregory Wohl provided expertise and feedback on the manuscript. Ana Pejović-Milić designed and financed the study, provided essential feedback, and approved the final manuscript. 


\subsection{Abstract}

Introduction: Osteoporosis is a debilitating disease that leads to the loss of bone mass, a prevalent health issue in the northern countries such as Canada. Strontium based supplements, such as strontium ranelate (Protelos), have been suggested to have therapeutic effects for the condition. Other strontium supplements, such as strontium salts available off-shelf in stores in Canada (e.g., strontium citrate), have been assumed to provide the similar effect as the strontium ranelate. The objective of this study was to compare the distribution of strontium in animal bones following administration of strontium ranelate and strontium citrate. Materials and Methods: Skeletally mature (17 weeks old) SpragueDawley female rats were split into three groups and dosed daily over ten weeks with 174.3 $\mathrm{mg} / \mathrm{kg} /$ day of strontium ranelate and $235.7 \mathrm{mg} / \mathrm{kg} /$ day of strontium citrate; the third group received no strontium supplementation. The right forelimb bones (humerus, ulna) were collected from all animals and strontium distribution was mapped using 2D micro-XRF. In addition, 3D Dual Energy X-ray K-edge Subtraction imaging was subsequently performed at the Canadian Light Source. Results: The 2D elemental mapping revealed statistically significant differences in strontium and calcium levels between the samples from treated animals and non-treated animals $(p<0.001)$. 2D intensity maps of calcium and strontium demonstrated tendency for strontium to substitute for calcium. 3D elemental strontium maps obtained at Canadian Light Source showed that strontium was observed to be largely present in the trabecular regions under the epiphyseal (growth) plate with concentrations of approximately 5 to $15 \mathrm{mg} / \mathrm{cm}^{3}$ in the bones of both strontium-treated groups. 
The thickness of the strontium layers in both the strontium ranelate and strontium citrate sample were not significantly different $(p=0.9201)$. The level of elemental strontium in the control bones was below the detection limit demonstrating a significant difference in bone strontium distribution between the rats receiving a normal diet and those receiving the strontium supplementation. Conclusions: The 2D images and data further support previous knowledge that strontium substitutes for calcium in newly formed bone during treatment in bone samples obtained from animals in both treatment groups. In addition, 3D images showed that both strontium ranelate and strontium citrate were effective in delivering elemental strontium to the bones of treated rats.

\subsection{Introduction}

Osteoporosis is a bone degenerating disease that is especially prevalent in northern countries where sun exposure is lower and temperatures are generally colder compared to other regions (Kapiczko et al, 2014). Increased fragility and decrease in bone mineralization due to osteoporosis can lead to a lifetime of complications such as osteoporotic fractures and pain (Riedel et al, 2017). This condition affects 1 in 3 women and 1 in 5 men in Canada alone (Osteoprosis Canada). Strontium ranelate is an alternative to other osteoporosis drugs, such as biophosphonates, parathyroid hormone (PTH) and selective estrogen receptor modulators (SERMs), in the treatment of women suffering from postmenopausal osteoporosis (Komrakova et al, 2015). The primary objective of this drug is to deliver elemental strontium to the bones of patients suffering from osteoporosis. Stron- 
tium is a table IIA element that is usually found in trace amounts in calcified tissue of non-treated individuals where natural intake of strontium is from the consumption of foods such as seafood, vegetables and cereals (Tournis et al, 2006).

Strontium taken as strontium ranelate has been shown to increase the strength of bone if delivered in non-toxic amounts, leading to decreased risk of osteoporotic fracture (Ammann et al, 2004; Tournis et al, 2006; Boivin et al, 2012; Komrakova et al, 2015). Newly formed bone is able to incorporate new elements, including strontium, into the hydroxyapatite crystal, predominantly through ionic substitution and surface exchange of calcium atoms on hydroxyapatite crystal (Riedel et al, 2017). It is reported that in subjects treated with strontium ranelate, approximately $5 \%(0.5: 10)$ to $10 \%(1: 10)$ of calcium atoms in hydroxyapatite are replaced or substituted by strontium atoms (Tournis et al, 2006; Li et al, 2010; Doublier et al, 2011; Pemmer et al, 2013). Strontium ranelate has been demonstrated to be a drug that increases bone strength and reduces the risk of vertebral bone fractures in postmenopausal women (Bonneyle et al, 2008). A "dual mode" of action is proposed as the main mechanism by which strontium ranelate achieves its effects in bone. It works by suppressing the breakdown of old bone by bone-resorbing osteoclasts cells, while at the same time affecting osteoblasts cells to promote formation of new hydroxyapatite during the bone turnover process (Bonneyle et al, 2008; Almeida et al 2016), although the exact process is still under investigation (Bain et al, 2009). Studies have been dedicated to investigating the distribution of elemental strontium in the bones of animals and humans treated with strontium ranelate. Humans consuming normal (trace) dietary 
levels of strontium have shown uniform distributions of strontium in different parts of the skeleton (Zamburlini et al, 2008). In contrast, strontium distribution in animals (monkeys, goats, and rats) receiving additional strontium supplementation from strontium ranelate, has been found to be heterogeneously distributed in newly formed bone during the treatment period (Oliveira et al, 2012), a trend also seen in postmenopausal women receiving strontium ranelate (Boivin et al, 2012). Structurally, bone is classified into two categories; trabecular or cancellous bone primarily found within the heads of long bones and cortical bone which primarily comprises bone cortex. Among newly formed hydroxyapatite, elemental strontium was favorably distributed in trabecular bone over cortical bone $\mathrm{Wu}$ et al, 2013; Boivin et al, 2012). Strontium ranelate has been demonstrated to have positive effects on mechanical and intrinsic bone properties without significant changes to microarchitecture in bone formed during treatment (Ammann et al, 2004; Bain et al, 2009).

The literature on the benefits of using strontium ranelate is extensive; however, the drug is only approved for use in Europe. In Canada compounds that deliver daily dosages of elemental strontium in the form of strontium citrate, strontium lactate, or strontium gluconate, are available as natural health products (Health Canada, 2015). Furthermore, recent studies have shown that long-term administration of strontium ranelate has increased the risk of cardiovascular disease particularly in hypertensive patients (Reginster et al, 2015), which may work against any future approval of the drug in North America. Since 2014, strontium ranelate has been contraindicated in patients with history of cardiovascular conditions and disease in European countries where the drug is most com- 
monly prescribed (Reginster et al, 2015; EMA, 2014). Nevertheless, it is still the treatment of choice for the patients who are not able to take other osteoporosis medications (EMA, 2014). However, little research has been conducted into alternative strontium salts that can provide similar health benefits as strontium ranelate, such as strontium citrate, strontium chloride, strontium carbonate, strontium lactate and strontium gluconate (Zamburlini et al, 2008). Conversely, other strontium salts taken as anti-osteoporotic treatments also present the potential to result in increased cardiovascular risks, however, this also remains to be investigated. The preceding study performed by our group on nineteen female Sprague-Dawley rats supplemented with strontium ranelate and strontium citrate suggests that both strontium salts are equally effective in delivering elemental strontium to the bones of rats (Wohl et al, 2013).

The distribution of elemental strontium in calcified tissue has been extensively investigated using a variety of imaging modalities such as micro-computed tomography $(\mu \mathrm{CT})$, electron probe microanalysis (EPMA), and X-ray cartography among others. The investigation of bone microarchitecture and trace-element distribution has made a transition to 2D and 3D methods of X-ray based microanalysis in recent years (Cooper et al, 2012). Micro X-ray fluorescence spectroscopy (micro-XRF) techniques use X-ray optics to produce smaller X-ray source focal spots that allow the excitation and therefore analysis of much smaller areas resulting in increased resolution (Smolek et al, 2014; Cordes et al, 2014).

The objective of the present study is to further examine the spatial and quantitative distribution of elemental strontium by using X-ray based imaging techniques in bone 
samples harvested from strontium ranelate and strontium citrate treated and non-treated animals from the preceding study of our group (Wohl et al, 2013). The strontium elemental maps have been produced using a custom 2D micro-XRF analysis and 3D dual energy Kedge subtraction (KES) imaging.

\subsection{Methods}

\subsubsection{Animal Model}

The animal bones used in this study were collected from a group of nineteen female Sprague-Dawley rats that were treated over a period of ten weeks (Wohl et al, 2013). The rats were separated into three groups; six (6) rats received $625 \mathrm{mg} / \mathrm{kg} /$ day of strontium ranelate, seven (7) rats received $676 \mathrm{mg} / \mathrm{kg} /$ day of strontium citrate via a flavoured gelatin suspension, and the remaining six (6) rats were left as a control group and received daily doses of only the flavoured gelatin vehicle. The goal of the preceding study was to perform in vivo XRF measurements to determine the accumulation of elemental strontium at various stages of feeding. Daily dosage was calculated with the aim of delivering 213 $\mathrm{mg} / \mathrm{kg} /$ day of elemental strontium to bones of the rats in the treated groups, however, the in vivo measurements showed discrepancies between the strontium signals. The actual amount of elemental strontium received by the rats was $173.4 \mathrm{mg} / \mathrm{kg} /$ day and 235.7 $\mathrm{mg} / \mathrm{kg} /$ day from strontium ranelate and strontium citrate, respectively, as measured by energy dispersive spectrometry (EDS) microanalysis (Wohl et al, 2013). Rats were sacri- 
ficed using $\mathrm{CO}_{2}$ inhalation, the right forelimbs were disarticulated and removed from the main body of the animal and subsequently frozen at $-20^{\circ} \mathrm{C}$ for storage and preservation.

\subsubsection{Sample Preparation}

All bone samples imaged in this work consisted of humerus bones from the right forelimbs harvested from the animal study conducted by Wohl and colleagues (2013). Three bones for the 2D imaging, one from each treatment group, were defrosted and submerged in cold $70 \%$ ethanol and shipped to Vienna for a preparation at the Ludwig Boltzmann Institute for Osteology. The long bones were cut transversally at the mid-shaft portion in preparation for the defatting and dehydration process. Sample preparation took approximately two weeks; bones were submerged in solutions of increasing ethanol concentration $(80 \%$ $100 \%$ ). Once the dehydration and defatting process has been completed, the bones were embedded in PMMA resin. The resulting thick blocks were cut into thin sections $(10-20$ $\mu \mathrm{m})$ and placed between two $8.0 \mu \mathrm{m}$ Kapton films (Table 2.1).

Bone samples selected for the 3D imaging at Canadian Light Source were dehydrated in $70 \%$ ethanol solution for two weeks and air dried for one week prior to the imaging. Samples were cut in-house in order to reduce their transverse thickness to no more than 2.0-3.0 mm using a diamond-wafering blade (IsoMet Low Speed Saw, Buehler). The heads were cut longitudinally to achieve the desired thickness by removing the epiphysis (head) from the diaphysis (shaft) of each sample. A total of eight samples were successfully scanned and their images reconstructed; four from the strontium ranelate group, two 
Table 2.1: Bone samples used for 2D micro-XRF and 3D dual energy KES imaging.

\begin{tabular}{ccc}
\hline \hline Sample & Sample Type & Thickness \\
\hline & 2D Imaging & \\
\hline Strontium ranelate & Thin block & $10 \mu \mathrm{m}$ \\
Strontium citrate & Thin block & $20 \mu \mathrm{m}$ \\
Control & Thin block & $18 \mu \mathrm{m}$ \\
\hline \multicolumn{3}{c}{ 3D Imaging } \\
\hline Strontium ranelate & Humeral head & $<2.0 \mathrm{~mm}$ \\
Strontium ranelate & Humeral head & $<2.0 \mathrm{~mm}$ \\
Strontium ranelate & Humeral head & $<2.0 \mathrm{~mm}$ \\
Strontium ranelate & Medial portion (shaft) & $<2.0 \mathrm{~mm}$ \\
Strontium citrate & Humeral head & $<2.0 \mathrm{~mm}$ \\
Strontium citrate & Humeral head & $<2.0 \mathrm{~mm}$ \\
Control & Humeral head & $<2.0 \mathrm{~mm}$ \\
Control & Humeral head & $<2.0 \mathrm{~mm}$ \\
\hline \hline
\end{tabular}

from the strontium citrate group, and two from the control group.

\subsubsection{D micro-XRF Elemental Strontium Mapping}

The three thin block samples from each treatment group (strontium ranelate, strontium citrate, control) were analyzed by 2D scanning different regions of interest containing trabecular and cortical bone using a low power $(20 \mathrm{~W})$ rhodium $(\mathrm{Rh})$ anode tube (Microfocus Oxford Apogee) and a $125 \mu \mathrm{m}$ Beryllium (Be) exit window (22). Emitted fluorescence from the samples was detected using a $30 \mathrm{~mm}^{2} \mathrm{Si}(\mathrm{Li})$ detector $(\mathrm{e} 2 \mathrm{v}, \mathrm{UK})$ with ultrathin polymer window (UTW, AP 3.3). In order to determine the correct regions for scanning, the liveview provided by the CDD camera built in the system (Allied Vision Marlin) coupled with a microscope (Mitutoyo M Plan Apo, 10x magnification, $3.5 \mu \mathrm{m}, 33.5 \mathrm{~mm}$ working distance) allowed for optimization of the position and focus of the sample. Furthermore, before the areal scan was performed, line scans over the depth of the samples were car- 
ried out on the corners of each region of interest $200 \mu \mathrm{m}$ above and below the z-position in order to determine the plane with the strongest strontium signal. Scanning parameters for all measurements were a step-size of $50 \times 50 \mu \mathrm{m}^{2}$, acquisition time of $100 \mathrm{~s}$ per point, the X-ray tube was set to a current of $0.4 \mathrm{~mA}$ and a voltage of $50 \mathrm{kV}$.

Deconvolution of the spectra was performed using AXIL (QXAS, IAEA Laboratories Seibersdorf, Seibersdorf, Austria). Elemental maps were generated using the X-ray lab software developed in-house at the Atominstitut, Vienna, Austria (Smolek et al, 2014). It has been reported that strontium incorporates itself into the matrix of the bone via substitution of calcium atoms, therefore, the strontium and calcium signals are assumed to approximate to $100 \%$ signal from calcified tissue within a reasonable standard deviation as other elements are known to also incorporate in bone such as $\mathrm{Pb}$ and $\mathrm{Zn}$ (Barry et al, 1975; Pemmer et al, 2013). The relative contribution of strontium [Sr] and calcium [Ca] in the strontium ranelate, strontium citrate, and control area scans was determined using Image (Version 1.50j). In order to eliminate information that did not corresponding to bone tissue in the images; the calcium maps were used to determine an appropriate intensity threshold that would correspond signal originating only from bone. In creating a threshold, the area corresponding to calcified tissue was selected to create a "mask" that could be superimposed on the corresponding strontium map to also eliminate pixels that did not contribute to signal originating from bone. These masks allowed the direct analysis of regions with calcium and strontium signals originating from bone within each image. The corresponding calcified regions in the strontium maps were selected using the 
calcium maps. The signals of strontium and calcium in these specific regions were added to create a map of $100 \%$ signal from bone. Finally, the strontium and calcium signals were individually divided by the addition of both signals, resulting in maps that showed the percent contribution of each element in the sample,

$$
\begin{gathered}
\% \mathrm{Ca}=\frac{[\mathrm{Ca}]}{[\mathrm{Sr}+\mathrm{Ca}]} \\
\% \mathrm{Sr}=\frac{[\mathrm{Sr}]}{[\mathrm{Sr}+\mathrm{Ca}]}
\end{gathered}
$$

where $[\mathrm{Sr}]$ and $[\mathrm{Ca}]$ are the absolute intensities from strontium and calcium signals and $[\mathrm{Sr}+\mathrm{Ca}]$ is cumulative calcium and strontium signal. It should be emphasized that these are not mass percentages but the ratios of counts. The resulting images showed the relative contribution of both elements in each sample for every scan. ImageJ was also used to analyze the maps to determine the mean and standard deviation of the relative elemental contribution for calcium and strontium. This process was performed for a total of seven different scans: three were of the strontium ranelate, two of the strontium citrate, and two of the control samples.

\subsubsection{D Dual Energy K-edge Subtraction X-ray Imaging}

Eight bone samples from the strontium citrate, strontium ranelate, and control groups were scanned using the BioMedical Imaging and Therapy-Bending Magnet (BMIT-BM) beamline at the Canadian Light Source (CLS). The detector system was a AA60 beam 
monitor (scintillator/optics combination) combined with Hamamatsu 1394 ORCA FLASH 4.0 camera (Hamamatsu City, Shizuoka Pref. Japan) set to a resolution of $13 \mu \mathrm{m}$. The source-to-sample distance was $25 \mathrm{~m}$ while the sample-to-detector distance was $0.2 \mathrm{~m}$. Prepared samples were mounted on screws with super glue and allowed to dry for a minimum of one hour to ensure that the adhesive had sufficient time to fully set before any measurement was performed, thus eliminating any movement during image acquisition and, therefore, minimizing motion artifact.

The region of interest for $\mu \mathrm{CT}$ was selected on live view. The epiphyseal (growth) plate was selected as the reference point for all measurements as it was easily observed in the live images. KES imaging requires collection of two datasets for each sample at two energies; one below $(16.085 \mathrm{keV})$ and the second one above $(16.185 \mathrm{keV})$ the K-edge of strontium $(16.105 \mathrm{keV})$. Theoretical K-edge energy value for strontium is $16.105 \mathrm{keV}$, however, we observed the K-edge crossing on a strontium phantom at $16.135 \mathrm{keV}$, thus the 'above' and 'below' energies were selected $\pm 50 \mathrm{eV}$ of that energy. One thousand eight hundred projections were acquired using a rotational step-size of 0.1 degrees over a total of 180 degrees. A $0.5 \mathrm{~mm}$ aluminum filter was used. The beam after monochromator was detuned to $40 \%$ of the maximum intensity to reduce the contribution from the silicon crystal $(2,2,0)$ higher order harmonics being counted as the imaging X-ray. The difference in linear attenuation coefficients for the 'above' and 'below' energies allow for the specific identification and mapping of the element of interest (in this case strontium); $1.098 \times 10^{2} \mathrm{~cm}^{2} / \mathrm{g}$ for the 'above' and $1.721 \times 10^{1} \mathrm{~cm}^{2} / \mathrm{g}$ for the 'below' energy (NIST, X-ray 
Mass Attenuation Coefficients). The change in linear attenuation coefficients for other materials not containing strontium is negligible, though was included for quantification of the concentrations. Dark and flat field scans ( $n=10$ projections) without the sample in the field of view were taken before and after each scan to correct for the excitation photon current decay during the scan. After flat-field and ring decay corrections, images were reconstructed, and the two data sets were co-registered in 3D to account for possible movements (normally less than 1 pixel between the scans). The reconstructed images from the 'above' and 'below' energies were subtracted in order to obtain the strontium maps. The subtraction yielded strontium concentration. For more details on quantification procedure used in this refer to the paper by Cooper et al, 2012. Strontium distribution maps were superimposed on the 'below' $\mu \mathrm{CT}$ data set in order to add bone micro-structural information. Scanning time varied between 45 to 90 minutes per energy scan, depending on the photon current of the storage ring of the synchrotron, which decays with time from $250 \mathrm{~mA}$ after each electron injection. Eight bone samples were imaged over a period of 48 hours.

The tomographic images were corrected for the ring decay (flat-field correction) using the flat and dark field images with ANKAphase (Weitkamp et al, 2011) and reconstructed using NRecon software (Bruker). Co-registration and subtraction of the "above" and "below" images to remove soft and calcified tissue contribution was performed on AVIZO (FEI). The thickness of the strontium layer in each 3D strontium map was determined using image $\mathrm{J}$ by choosing three random points along the epiphyseal plate and performing 


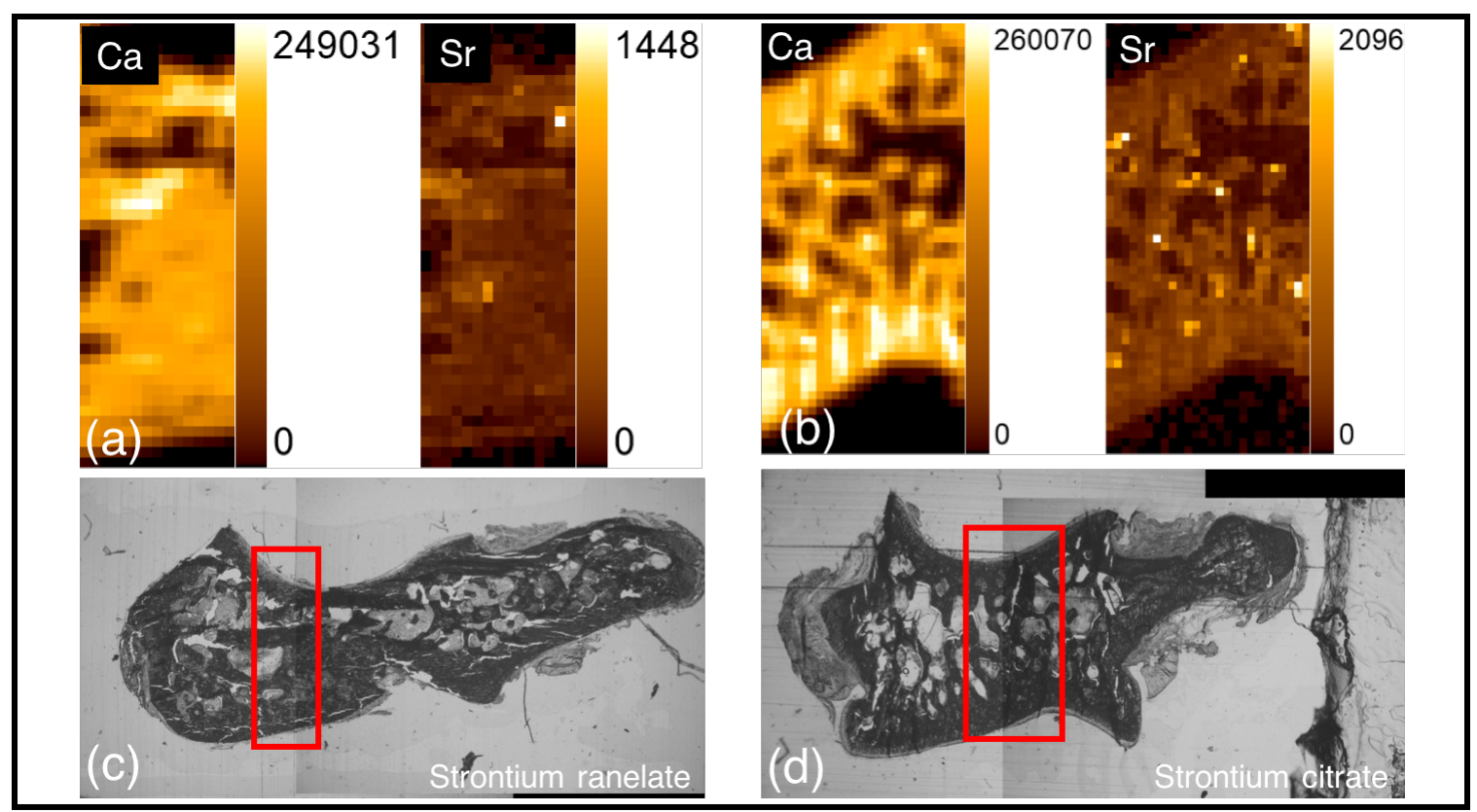

Figure 2.1: 2D elemental maps of calcium (Ca) and strontium ( $\mathrm{Sr}$ ) for, (a) strontium ranelate $(15 \times 43$ pixels), and (b) strontium citrate $(26 \times 55$ pixels $)$. Elemental maps are displayed in terms of absolute intensities. The images below the maps are electron light microscopy scans used to select the regions of interest (c) strontium ranelate, and (d) strontium citrate; regions scanned are indicated using a red frame.

manual measurements (Table 2.3).

\subsection{Results}

\subsubsection{D Elemental Strontium Images}

Three areal scans of the strontium ranelate sample, two of the strontium citrate sample and two of the control were taken resulting in elemental maps of calcium and strontium for each sample per scan. Elemental maps of calcium and strontium (Figure 2.1 (a) and (b)) show the distribution of these elements in strontium ranelate and strontium citrate treated 
Table 2.2: Percent calcium contribution \% $\mathrm{Ca}$ and percent strontium contribution $\% \mathrm{Sr}$ in bones supplemented with strontium ranelate and strontium citrate as well as no supplementation (control). The area of each selected region is given in pixels $\left(50 \times 50 \mu \mathrm{m}^{2} /\right.$ pixel $)$

\begin{tabular}{cccccc}
\hline $\begin{array}{c}\text { Sample } \\
\text { Type }\end{array}$ & $\begin{array}{c}\text { Area } \\
(\text { pixels })\end{array}$ & $\begin{array}{c}\text { Mean } \\
(\% \mathrm{Ca})\end{array}$ & $\begin{array}{c}\text { Standard } \\
\text { Deviation }(\% \mathrm{Ca})\end{array}$ & $\begin{array}{c}\text { Mean } \\
(\% \mathrm{Sr})\end{array}$ & $\begin{array}{c}\text { Standard } \\
\text { Deviation }(\% \mathrm{Sr})\end{array}$ \\
\hline Strontium ranelate & 399 & 99.76 & 0.1800 & 0.2400 & 0.1800 \\
Strontium ranelate & 912 & 99.90 & 0.0800 & 0.1000 & 0.0800 \\
Strontium ranelate & 498 & 99.89 & 0.0900 & 0.1100 & 0.0900 \\
Strontium citrate & 292 & 99.86 & 0.0600 & 0.1400 & 0.0600 \\
Strontium citrate & 918 & 99.76 & 0.1800 & 0.2400 & 0.1800 \\
Control & 594 & 100.0 & 0.0064 & 0.0042 & 0.0064 \\
Control & 286 & 99.99 & 0.0085 & 0.0073 & 0.0085 \\
\hline
\end{tabular}

bone samples. Figure 2.1(b) shows the the elemental map for strontium (Sr) and calcium (Ca), where hotspots are resulting from high calcium signal (bright yellow) correspond with regions of low intensity (dark) from strontium. These images visually demonstrate that strontium substitutes for calcium, thus one would expect to see low concentrations of strontium where concentrations of calcium are, as confirmed in these images.

The mean and standard deviation of calcium [Ca] and strontium [Sr] in seven scans (three for strontium ranelate, two for strontium citrate, and two for control) are shown in Table 2.2. Weighted (pooled) mean and standard deviations for each sample were determined. Strontium ranelate and strontium citrate treated bones showed significant differences in calcium levels $(p<0.001)$ where average calcium levels were higher in the strontium ranelate samples. The calcium levels in both treated samples were lower on average when compared to the non-treated (control) sample $(p<0.001)$, at a $95 \%$ confidence interval. The average strontium levels in the strontium citrate sample was $0.04 \%$ greater than the average strontium levels in the strontium ranelate sample $(p<0.001)$. 
Table 2.3: Strontium layer thicknesses taken at three different spots under the epiphyseal plate for the samples shown in Figure 2.2.

\begin{tabular}{ccccc}
\hline & \multicolumn{4}{c}{ Strontium Layer Thickness $(\mathrm{mm})$} \\
\hline & Location \#1 & Location \#2 & Location \#3 & Average \\
\hline Strontium ranelate & $1.44 \pm 0.02$ & $1.36 \pm 0.02$ & $1.30 \pm 0.02$ & $1.36 \pm 0.04$ \\
strontium citrate & $1.20 \pm 0.02$ & $1.24 \pm 0.02$ & $1.71 \pm 0.02$ & $1.38 \pm 0.04$ \\
\hline
\end{tabular}

The average strontium levels were also higher in both treated bone samples when compared to the levels in the un-treated sample $(p<0.001)$. Strontium levels in the treated animal bones are approximately $100 \times$ greater than in the control bones; demonstrating the ability of the hydroxyapatite to incorporate elemental strontium independently of the administered strontium salt.

\subsubsection{D Elemental Strontium Images}

Strontium 3D K-edge subtraction mapping yielded the maps that demonstrated the 3D distribution and concentrations of strontium accumulated in the bones of the two animal groups treated with the strontium salts (Figure 2.2). A high accumulation of strontium is observed below the epiphyseal plate (growth plate) in the humeral heads of the bones harvested from the strontium ranelate and strontium citrate treated animals (figure 2.2 (a) and (b)). These images provided a spatial distribution as well as the concentration $\left(\mathrm{mg} / \mathrm{cm}^{3}\right)$ of strontium accumulated in the bones over the ten weeks and further demonstrate that strontium is deposited in the bones independently of the strontium salt added to the diet. In an agreement with the literature, strontium was observed to be largely present in the trabecular regions, near the epiphyseal plate, in both strontium treated groups. Strontium 

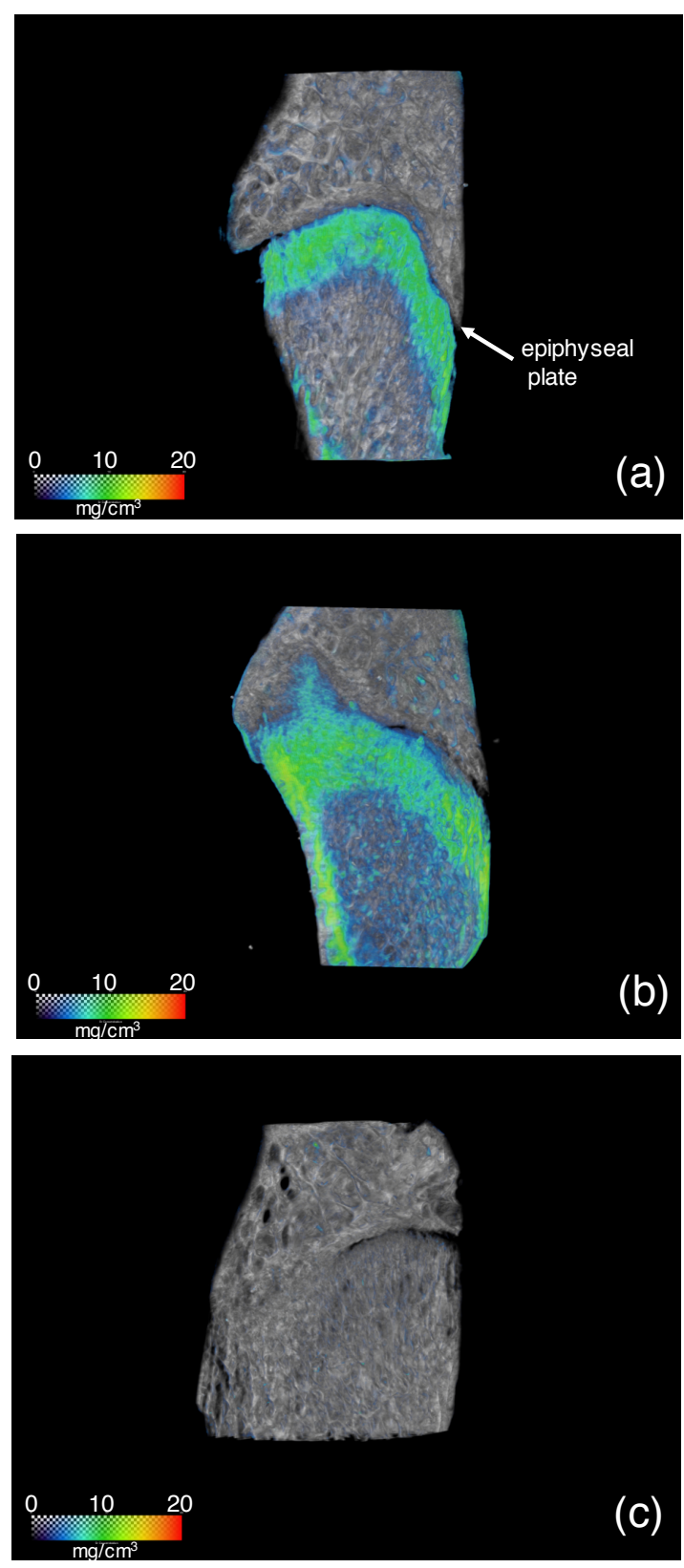

Figure 2.2: Cross-sections of the 3D elemental strontium maps of rat bones treated with, (a) strontium ranelate, (b) strontium citrate, and (c) control (non-treated). Images (a) through (c) depict the epiphyseal plate within the head of each proximal humerus. 


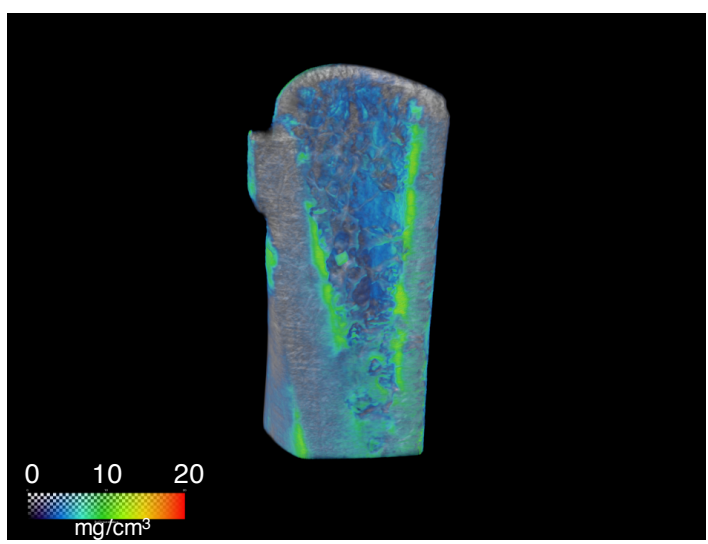

Figure 2.3: An elemental strontium map of the medial (shaft) of one of the strontium ranelate samples.

concentrations in these regions varied between 5 and $15 \mathrm{mg} / \mathrm{cm}^{3}$ in both groups. Bone scans for the controls confirmed that the levels of strontium are very low, with only a few spots (dark blue) seen in Figure 2.2(c). This suggests the presence of trace-levels of strontium, which are below the limits of detection of the K-edge subtraction imaging. Table 2.3 presents the thickness of strontium accumulated in the newly formed bone during the ten week feeding period. These strontium layers were measured under the epiphyseal plate at three different locations. The average strontium layer thickness was $1.364 \pm 0.039 \mathrm{~mm}$ and $1.382 \pm 0.036 \mathrm{~mm}$ in strontium ranelate and strontium citrate treated bones, respectively. The average thickness of the strontium layers in the two treated samples (figure 2.2 (a) and (b)) were not significantly different $(p=0.9201)$.

Figure 2.3 depicts elemental strontium distribution primarily in the endosteum layer of the mid-shaft of an animal treated with strontium ranelate. The portions of high concentration (bright green) of elemental strontium in the cortical shaft demonstrate comparable levels to those in the humeral head of the same bone. Due to time constraints at the 
beamline, only one shaft from a strontium ranelate sample was imaged.

\subsection{Discussion}

Strontium ranelate has been used as an effective therapeutic treatment in battling osteoporosis in women (postmenopausal) and men (Meunier et al, 2004; Seeman et al, 2006; Misiorowski et al, 2017; Pan et al, 2017). It has been shown that strontium ranelate is capable of improving intrinsic bone tissue quality of osteoporotic bone and reducing the risk of fractures associated with the disease in various animal models as well as in humans (Ammann et al, 2005; Seeman et al, 2006; Roschger et al, 2010; Boivin et al, 2012; Reginster et al, 2015). Minimal research has been conducted into the ability of other strontium salts in providing similar health benefits as strontium ranelate (Zamburlini et al, 2009). To date, the work of our group is the first study exploring the distribution of elemental strontium in bones obtained from an animal study involving the administration of strontium ranelate and an alternative strontium salt, strontium citrate. The in vivo and ex vivo analytical methods were used to determine the levels of bone strontium incorporation before and during the administration of salts as well as after sacrificing the rats in the preceding study. We expanded the work reported by Wohl and colleagues by utilizing Xray based imaging methods to provide spatial and quantitative distribution of strontium in the bones of the animals treated with the two mentioned strontium salts.

2D micro-XRF imaging provided elemental maps of small areas selected within the humerus bone of the right forelimb from each of the three treatment groups. The data 
obtained from processing the strontium and calcium signals allowed us to directly compare the average contribution of each element in the calcified tissue (Table 2.2). Elemental strontium and calcium levels have been reported to be heavily dependent on the degree of mineralization and, therefore, their relative contributions to calcified tissue are dependent on each other (Pemmer et al, 2013). It was expected that there would be detectable differences in calcium and strontium content when the strontium ranelate and strontium citrate samples were compared as the animals in the latter group received $35 \%$ more free ionic daily strontium.

The preceding study suggests that the calcium content in ashed tibias, as determined by inductively coupled plasma mass spectroscopy (ICP-MS), of the same animals as the ones used in this study tended to be less in the treated animals than in the control group, although no significant differences between calcium levels were reported (Wohl et al, 2013). Similarly, levels of calcium between treated and control bones imaged showed significantly less calcium present in treated rat bones $(p<0.001)$ when the percent contribution ratios of calcium were compared using a pooled mean t-test. This difference in calcium levels could be attributed to the fact that strontium is incorporated into the bone via substitution and surface exchange of calcium atoms in the hydroxyapatite crystal in animals suggesting the same mechanism of strontium incorporation for both salts (Doublier et al, 2013; Riedel et al, 2017). Furthermore, the strontium ranelate sample had higher calcium concentrations than the strontium citrate sample $(p<0.001)$. This difference could be associated with the $35 \%$ higher daily dose of strontium citrate administered to rats, which 
therefore was incorporated more into bone by replacing calcium.

The strontium levels in the treated bone samples were approximately two orders of magnitude higher than in the control bones, an expected result due the high daily dosage of elemental strontium received by both treated groups. Elemental strontium levels in the strontium citrate sample were $0.04 \%$ greater than in the strontium ranelate sample $(p<0.001)$. This is in agreement with the fact that the strontium citrate animals received more daily strontium. However, Wohl and colleagues reported that the $\mathrm{Sr} / \mathrm{Ca}+\mathrm{Sr}$ ratio in strontium samples was $32.7 \%$ greater than in the strontium ranelate bones analyzed, which is not observed in the images provided in this work. It is important to emphasize that the 2D images were each obtained from one animal forelimb from each treated group and only small areas within each humerus were imaged, thus the information for the entire sample is not available as was true in the ICP-MS ashed tibia measurements. Another reason for the difference in strontium levels observed between the preceding study and this study is due to two different bones analyzed, namely, the tibia and humerus. It is documented that strontium is incorporated at different rates in bone depending on the location in the skeleton. Finally, it is worth mentioning strontium content in the control bones yielded weak fluorescent signals.

The K-edge subtraction imaging provided excellent 3D data that showed the localization of elemental strontium on the distal side of the growth plate in the humeral head of the right forelimbs in bones from the treated groups. Strontium was detected (figure 2.2 (a) and (b)) in cortical and trabecular tissue with the majority being found in the lat- 
ter, which is in agreement with current knowledge (Li et al, 2010; Boivin et al 2010), and the fact that bone turnover is higher in trabecular bone, hence allowing more strontium to be incorporated in the bone. This is further confirmed by the significant accumulation of strontium found in the region directly under the growth plate primarily composed of newly formed trabecular bone, and is the area of highest bone turnover (Clarke, 2008). The strontium deposition on the primary ossification side of the metaphysis indicates that there was new bone formation at the growth plate as part of endochondral bone growth. Strontium is heterogeneously spread throughout the distal head of the humerus with concentrations ranging approximately between $5 \mathrm{mg} / \mathrm{cm}^{3}$ and $15 \mathrm{mg} / \mathrm{cm}^{3}$ in all treated bones imaged (figure 2.2 (a) and (b)).

The thickness of the strontium layer is similar between both treated groups as can be seen in Table 2.3. The thickness of the strontium layer below the epiphyseal plate was a feature observed in all images of treated bones suggesting that accumulation of elemental strontium is time dependent. The thickness of the strontium layer in the strontium ranelate sample was between $1.30 \pm 0.02 \mathrm{~mm}$ at the thinnest portion and $1.44 \pm 0.02$ $\mathrm{mm}$ at the thickest. Similarly, the thickness in the strontium citrate samples was between $1.19 \pm 0.02 \mathrm{~mm}$ and $1.71 \pm 0.02 \mathrm{~mm}$. The average strontium layer thickness for the strontium ranelate and strontium citrate samples was $1.36 \pm 0.04 \mathrm{~mm}$ and $1.38 \pm 0.04 \mathrm{~mm}$, respectively. There were no significant differences in thicknesses between the treated bone samples at the $95 \%$ confidence interval $(p=0.9201)$. Keeping in mind the fact that strontium citrate treated animals received 35\% more elemental strontium than their strontium ranelate 
counterparts, this result could be explained if strontium from both salts was incorporated into the bones of rats at different rates and therefore suggesting that more strontium citrate is required to achieve similar levels of strontium in bone compared to strontium ranelate. Alternatively, the data could also suggest strontium reaching a saturation point in bone and, therefore, due to the high concentrations of the drugs fed to the animals, this point may have been reached in both treatment groups, whether strontium accumulation continuously increases or reaches saturation over time is still under investigation (Moise et al, 2012; Moise et al, 2016).

Figure 2.3 shows a strontium map of the shaft (medial portion) of one of the strontium ranelate samples. The most prominent feature observed was the high concentration of strontium (bright green) at the endosteum, the boundary between the cortex and trabecular bone, which is in line with the knowledge that strontium is also incorporated into cortical bone over a prolonged treatment (Boivin et al, 2010). Furthermore, the trabecular region within the bone shaft also shows significant levels of strontium as can be seen in the dark blue portions of the image. The strontium ranelate shaft once again exemplifies the tendency for strontium to be heterogeneously distributed in bone formed during treatment as no strontium signal was detected in the inner portions of the cortex, a region which would already have been formed long before the supplementation. Because of this property, strontium has been used as a tracer of bone turnover (Panahifar et al, 2015).

In conclusion, the study investigated the spatial distribution of elemental strontium in rat bones administered with strontium ranelate, a commonly prescribed treatment for os- 
teoporosis, and strontium citrate, an off-shelf strontium salt that may serve as an equally suitable alternative (Cooper et al, 2012). X-ray based techniques were used to image and quantify strontium bone content by producing 2D maps using micro-XRF and 3D maps using dual energy K-edge subtraction imaging. The 2D elemental maps show significant differences in the bone strontium and calcium content between strontium ranelate and strontium citrate groups. Similar concentrations of strontium in both treated groups were observed, however, the strontium citrate sample had a higher average concentration of elemental strontium - consistent with the greater daily dose that was administered to the animals. The 3D maps demonstrated that elemental strontium is delivered to the same bone regions in both strontium ranelate and strontium citrate groups in similar concentrations. It was observed in the calcified region below the epiphyseal (growth) plate and the rest of the trabecular tissue. This data also showed that strontium taken during supplementation at high doses over a period of ten weeks could also accumulate in cortical regions of the bone, if sufficient bone remodeling occurs. 3D dual energy K-edge subtraction images showed the most comprehensive elemental strontium maps for rats treated with strontium citrate by providing high quality spatial and quantitative information, which was comparable to the results achieved by rats supplemented with strontium ranelate. This work highlights the advantages of using KES imaging coupled with synchrotron radiation to produce elemental strontium maps by demonstrating the amount of detail achievable with this technique. While the 3D elemental maps showed the accumulation below the epiphyseal plates of all bones imaged, these images still represent 
bone strontium maps in rats at one point in time during their supplementation at the end of ten weeks. Future 3D imaging studies could concentrate on obtaining images of bone samples from animals at different points of strontium salt administration in order to further compare the degree of strontium incorporation into bone. Neither imaging modality was able to detect any significant signals from strontium in calcified tissues of any control sample analyzed, suggesting only trace levels of strontium below the limits of detection of both systems in untreated samples. The incorporation of elemental strontium in the bones of animals appeared to be independent of the salt administered and accumulation occurs where active bone turnover occurs, in this case primarily under the epiphyseal plate of long bones. This work should stipulate the need to expand research into alternative strontium salts, such as strontium citrate, strontium carbonate, strontium lactate, strontium chloride, which are readily available options for the treatment or prevention of postmenopausal osteoporosis.

\section{Acknowledgements}

The authors would like to thank Dr. Adam Webb, beamline scientist at the BioMedical Imaging Therapy (BMIT) beamline at Canadian Light Source (CLS) for his assistance in setting up the experiment and CLS for granting the necessary beamtime to conduct the study. CLS is funded by the Canada Foundation for Innovation, the Natural Sciences and Engineering Research Council of Canada (NSERC), the National Research Council Canada, the Canadian Institutes for Health Research (CIHR), the Government of Saskatchewan, 
Western Economic Diversification Canada, and the University of Saskatchewan. Arash Panahifar is a Saskatchewan Health Research Foundation (SHRF) fellow. We would also like to acknowledge Dr. Paul Roscgher at the Ludwig-Boltzmann Institute for Osteology in Vienna, Austria for his assistance in preparing the thin bone samples for micro-XRF analysis. This work was supported by the NSERC. 


\section{Chapter 3}

\section{Conclusions and Future Work}

\subsection{Summary of the Study}

The development of osteoporosis in both men and women throughout the world continues to be a significant burden to patients suffering from the condition, despite the many options for treatment readily available. Strontium ranelate, a medication advertised for the treatment of osteoporosis, is becoming a popular alternative to reduce the risk of fractures associated with the disease. Since 2004, strontium ranelate has been the commonly prescribed strontium salt in Europe for osteoporotic patients after publication of the Spinal Osteoporosis Therapeutic Intervention (SOTI) and TReatment Of Peripheral OSteoporosis (TROPOS) studies (Meunier et al, 2004; Reginster et al, 2005). The manufacturers of strontium ranelate suggest that its therapeutic effects are attributed to a "dual-mode of action" mechanism whereby resorption of old bone is suppressed and excretion of new bone 
is stimulated (Bonneyle, Almeida). Whether this mechanism is truly responsible for the beneficial effects seen in humans and animals receiving the strontium-based medication is still under investigation (Hurtel-Lemaire et al, 2009). Alternative strontium sources, such as strontium citrate, are sold as supplements in health food stores, are believed to offer similar health benefits as strontium ranelate. However, their mechanism of incorporation in bone and health benefits are still unknown. Much investigation has yet to be done into other available strontium supplements to compare the ability of any strontium salt in delivering elemental strontium to the bones of humans and animals.

The objective of the preceding (Wohl et al, 2013) and present study was to aid in filling this gap in the literature into the potential health benefits of alternative strontium salts, such as strontium citrate, in comparison to strontium ranelate. Bone samples were obtained from the initial animal study of nineteen Sprague-Dawley rats that were supplemented with strontium ranelate and strontium citrate over a period of ten weeks. The study by Wohl and colleagues conducted an animal study and monitored strontium concentration in animal bone, in vivo and ex vivo. The present study evaluated the spatial and quantitative distribution of elemental strontium in bone samples from animals treated with each salt. Elemental strontium distribution was mapped using 2D micro X-ray fluorescence and 3D dual energy K-edge subtraction X-ray imaging techniques.

Micro X-ray fluorescence (micro-XRF) imaging demonstrated that it is suitable for producing 2D maps of elemental strontium with a resolution of $50 \times 50 \mu \mathrm{m}^{2}$ per pixel of thin sections cut from humerus bones of treated and non-treated animals. In addition 
to strontium maps, elemental maps of calcium were produced from the corresponding fluorescent signal from each of the areas scanned in all three samples. Percent relative contribution to calcified tissue from strontium \%Sr and calcium \%Ca was calculated as outlined in section 3.3 and subsequent statistical analysis of the data demonstrated that there were significant differences between the treated and non-treated groups at a 95\% confidence interval in terms of strontium and calcium levels. Average strontium levels in the strontium citrate sample was $0.04 \%$ higher than in the strontium citrate sample, this difference while small, was still significant $(p<0.001)$. Conversely, the calcium content in the strontium ranelate was $0.04 \%$ higher than in the strontium citrate sample $(p<0.001)$. The difference in strontium content can be attributed to the fact that the strontium citrate animals received approximately 35\% more elemental strontium than their strontium ranelate counterparts and assuming the tendency of strontium to substitute for calcium could explain the difference in calcium content between treated groups. Furthermore, the $2 \mathrm{D}$ images also showed visually that strontium incorporates for calcium at the same locations of bone as bone formed during the treatment.

The 3D dual energy K-edge subtraction (KES) images obtained at Canadian Light Source were particularly effective in showcasing the ability of both salts to deliver elemental strontium to the epiphyseal plates in the humerus bones from the front-right limbs of the rats. The strontium layer was visible and comparable in all the treated bones imaged. Thicknesses of the strontium layers of the strontium ranelate and the strontium citrate samples were evaluated using ImageJ, no significant difference in strontium layer thick- 
ness was found between the two evaluated samples $(p=0.9201)$. The high accumulation in this region is due to the high rate of bone turnover that occurs at the epiphyseal plate. Strontium citrate treated animals received more strontium than the strontium ranelate group, thus, the similarity in strontium layer thicknesses could be either explained by different rates of incorporation of strontium or that the levels of strontium reached a saturation point before the time of sacrifice ( 10 weeks into the treatment). This would suggest that strontium incorporation is time dependent, and in this case, that more strontium citrate is required to achieve the same endpoint as strontium ranelate. Furthermore, obtained 3D these results further confirm that elemental strontium is heterogeneously distributed throughout the bone. Higher concentrations of strontium were primarily found the trabecular regions of the bone samples and in some cortical portions in the cortex of all samples, including in the singular strontium ranelate shaft imaged. This high accumulation of strontium is localized in new hydroxyapatite formed during the course of the ten-week treatment at a high daily dose. Strontium concentrations ranged between 5 and $15 \mathrm{mg} / \mathrm{cm}^{3}$ in all bones imaged. In contrast, the image of the control sample displayed no strontium signal suggesting the lack of elemental strontium incorporated through normal diet or that strontium levels are below the limit of detection of KES.

It was demonstrated that the distribution of strontium contained within the bones of rats treated with high dosages (relative to their body weight) of strontium ranelate and strontium citrate can be effectively imaged using both 2D micro-XRF and 3D dual energy K-edge subtraction imaging. The micro-XRF study demonstrated that there were differ- 
ences in strontium and calcium content in the calcified tissues of the treated bone samples. The data appears to confirm that the higher strontium content observed in the strontium citrate sample is a reflection of these animals receiving 35\% more daily strontium as compared to those treated with strontium ranelate. The most prominent results stem from KES imaging that yielded 3D maps of elemental strontium primarily concentrated below the epiphyseal (growth) plate in the humeral heads of the bones treated with the same strontium salt. The strontium layer thickness of the strontium ranelate and strontium citrate bones were statistically the same. Overall, it can be concluded from the 2D and 3D data that the spatial distribution of strontium is independent of the strontium salt, however, the rate of accumulation of strontium delivered by either salt is still unclear. The limitations of this study result from the fact that all bones imaged in both X-ray studies were from rats of the same age and stage of supplementation. Furthermore, the two treated groups in this study did not receive the same amount of elemental strontium from each salt, therefore we were not able to directly compare the rate of accumulation of strontium or if there was indeed a saturation point or 'plateau' reached.

\subsection{Future Work}

The results presented in this work suggest elemental strontium distribution is both quantitatively and spatially independent of the strontium salt used as therapeutic drug, however, these results are still early and much work into comparing strontium ranelate to other strontium salts is required. As a result, these findings give rise to an opportunity 
to look into other strontium sources as alternatives to strontium ranelate. As previously mentioned, strontium carbonate, strontium lactate, strontium chloride and strontium gluconate are readily available in health food stores in Canada and the US as they do not require prescriptions and are not heavily regulated. The implications of these results can have a significant impact on the use of strontium for the treatment or prevention of osteoporosis. Despite the evidence that long-term use of strontium can lead to an increased risk of cardiovascular conditions, strontium ranelate remains a commonly prescribed antiosteoporotic drug, albeit with increased restrictions (European Medicines Agency, 2014). Therefore, strontium supplementation for the treatment of osteoporotic symptoms is an area of research that still holds a lot of merit.

Future steps of this work should continue in the direction of using dual energy K-edge subtraction for the purposes of imaging the distribution of strontium in animal bones if possible. The images showed that strontium is primarily accumulated under the epiphyseal plate in long bones receiving additional strontium. Thus future work could involve bone samples harvested from animals at different stages of equal strontium administration and then afterward perform similar imaging of the growth plate in order to truly understand the rate of accumulation of strontium in this region. Evaluation of the deposition of strontium at early (a few weeks) and late (a few months) stages of supplementation would give a broader picture of how strontium is incorporated into bone and would allow a temporal comparison of the distribution from two or more strontium salts. In addition, such a study would aid in the debate in literature on whether strontium is continually 
accumulated or reaches a saturation point (Moise et al, 2016; Oliveira et al, 2015; Moise et al, 2012). It has been demonstrated that strontium is accumulated at different rates in different parts of the skeleton (Komrakova et al, 2015), thus, similar imaging studies can be performed on other bones from an animal's body such as the femur and the spine in parallel to humeral heads to provide comparison between different locations of the skeleton.

Investigation into strontium salts can eventually lead to their widespread use, aiding in closing the osteoporosis treatment gap that has been observed in recent years. These alternative strontium salts potentially offer similar health benefits to osteoporotic women and men and are more readily available in health food stores without a prescription and a fraction of the cost of strontium ranelate. This work is the first report that strontium citrate deposits elemental strontium in a similar manner as strontium ranelate and that strontium incorporation is time-dependent. Strontium was heterogeneously distributed throughout the bone of both strontium ranelate and strontium citrate treated animals, with the strontium layer thickness below the epiphyseal plate being the same for both salts. In addition, 3D images also demonstrated that levels of elemental strontium were similar in both treated bones. These initial findings in the levels of strontium and calcium suggest that both salts deliver elemental strontium with similar efficacies, however, further investigation is required. 


\section{References}

1. Abrahamsen, B., Grove, E. and Vestergaard, P. (2013). Nationwide registry-based analysis of cardiovascular risk factors and adverse outcomes in patients treated with strontium ranelate. Osteoporosis International, 25(2), pp.757-762.

2. Almeida, Monica Marletti et al (2016). Strontium Ranelate Increases Osteoblast Activity. Tissue and Cell 48.3: 183-188.

3. Ammann P, Shen V, Robin B, Mauras Y, Bonjour JP, Rizzoli R. (2014). Strontium ranelate improves bone resistance by increasing bone mass and improving architecture in intact female rats. Journal of bone and mineral research. 19(12):2012-20.

4. Anatomy \& Physiology (2013). Illustration from Wikimedia. [Link]

5. Anne, J., Edwards, N., Wogelius, R., Tumarkin-Deratzian, A., Sellers, W., van Veelen, A., Bergmann, U., Sokaras, D., Alonso-Mori, R., Ignatyev, K., Egerton, V. and Manning, P. (2014). Synchrotron imaging reveals bone healing and remodelling strategies in extinct and extant vertebrates. Journal of The Royal Society Interface, 11(96), pp.1-10.

6. Atteritano, M., Catalano, A., Santoro, D., Lasco, A. and Benvenga, S. (2015). Effects of strontium ranelate on markers of cardiovascular risk in postmenopausal osteoporotic women. Endocrine, 53(1), pp.305-312.

7. Bain, S. D. et al (2009). Strontium Ranelate Improves Bone Strength In Ovariectomized Rat By Positively Influencing Bone Resistance Determinants. Osteoporosis International 20.8: 1417-1428.

8. Barry PS (1975). A comparison of concentrations of lead in human tissues. BR J Med 32:119-39

9. Bolland, M. J., and Grey, A. (2016). Ten years too long: Strontium ranelate, cardiac events, and the european medicines agency. BMJ : British Medical Journal (Online), 354.

10. Bonnelye, Edith et al (2008). Dual Effect Of Strontium Ranelate: Stimulation Of Osteoblast Differentiation And Inhibition Of Osteoclast Formation And Resorption In Vitro. Bone 42.1: 129-138.

11. Boivin G, Audrey D, and Delphine F (2012). Strontium Ranelate âĂŞ A Promising Therapeutic Principle In Osteoporosis. Journal of Trace Elements in Medicine and Biology 26.2-3: 153-156.

12. Boivin, G. et al (2010). In Osteoporotic Women Treated With Strontium Ranelate, Strontium Is Located In Bone Formed During Treatment With A Maintained Degree Of Mineralization. Osteoporosis International 21.4: 667-677. 
13. Cheung, T., Law, A., Ahmed, R., Mak, C. and Lau, C. (2016). Assessment of bone calcium and phosphorus content using micro X-ray fluorescence spectrometry $(\mu-$ EDXRF): effects of long-term cadmium poisoning. X-Ray Spectrometry, 45(6), pp.339343.

14. Chinchon-Paya, S., Aguado, A., Coloma, F. and Chinchon, S. (2013). Study of aggregate samples with iron sulfides through micro X-ray fluorescence ( $\mu \mathrm{XRF})$ and X-ray photoelectron spectroscopy (XPS). Materials and Structures, 48(5), pp.1285-1290.

15. Clarke, B. (2008). Normal Bone Anatomy and Physiology. Clinical Journal of the American Society of Nephrology, Supplement 3, S131-S139.

16. Cordes N, Havrilla G, Usov I, Obrey K, and Patterson B. (2014). Non-destructive elemental quantification of polymer-embedded thin films using laboratory based X-ray techniques. Spectrochimica Acta Part B: Atomic Spectroscopy, 101, pp.320329.

17. Cooper DML, Chapman L, Carter Y, Wu Y, Panahifar A, Britz H, Bewer B, Zhouping W, Duke M and Doschak M (2012). Three-dimensional mapping of strontium in bone by dual energy K-edge subtraction imaging. Physics in Medicine and Biology, 57(18), 5777-5786.

18. Curzon, M.E.J., Spector, P.C. (1977). Enamel Mottling in High Strontium Area of the USA. Community Dent. Oral Epidemiol. 5 243-7.

19. Doublier, A. et al (2011). Distribution Of Strontium And Mineralization In Iliac Bone Biopsies From Osteoporotic Women Treated Long-Term With Strontium Ranelate. European Journal of Endocrinology 165.3 (2011): 469-476

20. Doublier, A. et al (2013). Effects Of Strontium On The Quality Of Bone Apatite Crystals: A Paired Biopsy Study In Postmenopausal Osteoporotic Women. Osteoporosis International 24.3: 1079-1087.

21. European Medicines Agency. Protelos/osseor to remain available but with further restrictions. (2014) [Link]

22. Garrevoet, J., Vekemans, B., Bauters, S., Demey, A. and Vincze, L. (2015). Development and Applications of a Laboratory Micro X-ray Fluorescence ( $\mu \mathrm{XRF}$ ) Spectrometer Using Monochromatic Excitation for Quantitative Elemental Analysis. Analytical Chemistry, 87(13), pp.6544-6552.

23. Health Canada. Summary Safety Review - Strontium - Risk of Heart and Circulatory Side Effects - Canada.ca. (Oct. 2015) Canada.ca. [Link]

24. Hegde, V., Jo, J., Andreopoulou, P. and Lane, J. (2015). Effect of osteoporosis medications on fracture healing. Osteoporosis International, 27(3), pp.861-871. 
25. Hodges, R.M., MacDonald, N.S., Nusbaum, R., Stearns, R., Ezmirlian, F., Spain, P., and MacArthur, C. (1950) J. Biol Chem; 185:519.

26. Hurtel-Lemaire, A., Mentaverri, R., Caudrillier, A., Cournarie, F., Wattel, A., Kamel, S., Terwilliger, E., Brown, E. and Brazier, M. (2009). The Calcium-sensing Receptor Is Involved in Strontium Ranelate-induced Osteoclast Apoptosis. Journal of Biological Chemistry, 284(1), pp.575-584.

27. Kanis J, Svedbom A, Harvey N, and McCloskey E. (2014). The Osteoporosis Treatment Gap. Journal of Bone and Mineral Research, 29(9), pp.1926-1928.

28. Kapiczko A. Assessment of intake of calcium and vitamin D and sun exposure in the context of osteoporosis risk in a study conducted on perimenopausal women. Prz Menopauzalny 13(2), (2014): 79-83.

29. Komrakova, Marina et al. (2015). The Impact Of Strontium Ranelate On Metaphyseal Bone Healing In Ovariectomized Rats. Calcified Tissue International 97.4: 391401.

30. Lewiecki E, Boyle J, Arora S, Bouchonville M, and Chafey D. (2017) Telementoring: a novel approach to reducing the osteoporosis treatment gap. Osteoporosis International, 28(1), pp.407-411.

31. Li, C et al. (2010). Strontium Is Incorporated Into Mineral Crystals Only In Newly Formed Bone During Strontium Ranelate Treatment. Journal of Bone and Mineral Research 25.5: 968-975.

32. Li, X., Li, Y., Jin, W., Zheng, Y., Rong, C., Lyu, H. and Shen, H. (2014). Investigation of strontium accumulation on ovariectomized SpragueâĂŞDawley rat tibia by micro-PIXE. Nuclear Instruments and Methods in Physics Research Section B: Beam Interactions with Materials and Atoms, 332, pp.321-325.

33. Lima, I., Anjos, M., Fleiuss, M., Rosenthal, D. and Lopes, R. (2008). Characterization of osteoporotic bone structures by bidimensional images through x-ray microfluorescence with synchrotron radiation. X-Ray Spectrometry, 37(3), pp.249-254.

34. Liu Z, Weaver J, de Papp A, Li Z, Martin J, Allen K, Hui S. and Imel E. (2016). Disparities in osteoporosis treatments. Osteoporosis International, 27(2), pp.509-519.

35. Meunier PJ, Roux C, Seeman E, Ortolani S, Badurski JE, Spector T, Cannata J, Balogh A, Lemmel E, Pors-Nielsen S, Rizzoli R, Genant H, and Reginster J (2004). The Effects of Strontium Ranelate on the Risk of Vertebral Fracture in Women with Postmenopausal Osteoporosis. Obstetrical \& Gynecological Survey, 59(7), 526-527. 
36. Mierzwa, A., Campos, J., Jesus, M., Nader, H., Lazaretti-Castro, M. and Reginato, R. (2017). Different doses of strontium ranelate and mechanical vibration modulate distinct responses in the articular cartilage of ovariectomized rats. Osteoarthritis and Cartilage, 25(7), pp.1179-1188.

37. Misiorowski W. (2017). Osteoporosis in men. Menopausal Review, 2, pp.70-73.

38. Moise H, Adachi JD, Chettle DR, Pejović-Milić A. (2012). Monitoring Bone Strontium Levels Of An Osteoporotic Subject Due To Self-Administration Of Strontium Citrate With A Novel Diagnostic Tool, In Vivo XRF: A Case Study. Bone 51.1: 93-97.

39. Moise H, Chettle DR, and Pejović-Milić A. (2016). Modeling elemental strontium in human bone based on in vivo X-ray fluorescence measurements in osteoporotic females self-supplementing with strontium citrate. Physiological Measurement, 37(3), pp.429-441.

40. National Institute of Standards and Technology (NIST). X-ray Mass Attenuation Coefficients. [Link]

41. Naylor, K. and Eastell, R. (2012). Bone turnover markers: use in osteoporosis. Nature Reviews Rheumatology, 8(7), pp.379-389.

42. Neer RM, Arnaud CD, Zanchetta JR, Prince R, Gaich GA, Reginster JY et al (2001) Effect of parathyroid hormone (1-34) on fractures and bone mineral density in postmenopausal women with osteoporosis. N Engl J Med 344(19):1434âĂŞ1441.

43. Oliveira, Josianne P. et al (2012). Strontium Is Incorporated In Different Levels Into Bones And Teeth Of Rats Treated With Strontium Ranelate. Calcified Tissue International 91.3: 186-195.

44. Osteoporosis Canada. Osteoporosis Facts and Statistics. [Link]

45. Pan, W., Chen, P., Lin, C., Pan, Y., Ju, Y., Chan, C. and Hsu, R. (2017). Strontium ranelate treatment in a postmenopausal woman with osteonecrosis of the jaw after long-term oral bisphosphonate administration: a case report. Clinical Interventions in Aging, Volume 12, pp.1089-1093.

46. Panahifar A, Cooper DML, and Doschak MR (2015). 3-D localization of non-radioactive strontium in osteoarthritic bone: Role in the dynamic labeling of bone pathological changes. J Orthop 33(11):1655-62

47. Pemmer B, Roschger A, Wastl A, Hofstaetter JG, Wobrauschek P, Simon R, Thaler HW, Roschger P, Klaushofer K and Streli C (2013). Spatial Distribution Of The Trace Elements Zinc, Strontium And Lead In Human Bone Tissue. Bone 57.1: 184-193. 
48. Pemmer B, Hofstaetter J, Meirer F, Smolek S, Wobrauschek P, Simon R, Fuchs R, Allen M, Condon K, Reinwald S, Phipps R, Burr D, Paschalis E, Klaushofer K, Streli $\mathrm{C}$ and Roschger $\mathrm{P}$ (2011). Increased strontium uptake in trabecular bone of ovariectomized calcium-deficient rats treated with strontium ranelate or strontium chloride. Journal of Synchrotron Radiation, 18(6), pp.835-841.

49. Public Health Agency of Canada (2009). 2009 Canadian Community Health Survey, Government of Canada. [Link]

50. Querido, W., Campos, A., Martins Ferreira, E., San Gil, R., Rossi, A. and Farina, M. (2014). Strontium ranelate changes the composition and crystal structure of the biological bone-like apatite produced in osteoblast cell cultures. Cell and Tissue Research, 357(3), pp.793-801.

51. Reginster, JY. et al. The Position Of Strontium Ranelate In TodayâĂŹs Management Of Osteoporosis. Osteoporosis International 26.6 (2015): 1667-1671.

52. Reginster, J. (2014). Cardiac concerns associated with strontium ranelate. Expert Opinion on Drug Safety, 13(9), pp.1209-1213.

53. Riedel, Christoph et al (2017). The Incorporation of Fluoride And Strontium In Hydroxyapatite Affects The Composition, Structure, And Mechanical Properties Of Human Cortical Bone. Journal of Biomedical Materials Research Part A 105.2: 433442

54. Roschger P, Manjubala I, Zoeger N, et al (2010). Bone material quality in transiliac bone biopsies of postmenopausal osteoporotic women after 3 years of strontium ranelate treatment. Journal of Bone and Mineral Research: The Official Journal of the American Society for Bone and Mineral Research, 25(4), 891âĂŞ900

55. Seeman E, Vellas B, Benhamou C, Aquino J, Semler J, Kaufman J, Hoszowski K, Varela A, Fiore C, Brixen K, Reginster JY and Boonen S. (2006). Strontium Ranelate Reduces the Risk of Vertebral and Nonvertebral Fractures in Women Eighty Years of Age and Older. Journal of Bone and Mineral Research, 21(7), 1113-1120.

56. Shorr, E., Carter, A.C. (1952). Bull. Hosp. Joint Dis; 13:59.

57. Siccardi, A., Padgett-Vasquez, S., Garris, H., Nagy, T., D’Abramo, L. and Watts, S. (2010). Dietary Strontium Increases Bone Mineral Density in Intact Zebrafish (Danio rerio): A Potential Model System for Bone Research. Zebrafish, 7(3), pp.267-273.

58. Solomon DH, Johnston SS, Boytsov NN, McMorrow D, Lane JM, Krohn KD (2014) Osteoporosis medication use after hip fracture in U.S. patients between 2002 and 2011. J Bone Miner Res : Off J Am Soc Bone Miner Res 29:1929âĂŞ1937 
59. Smolek S, Nakazawa T, Tabe A, Nakano K, Tsuji K, Streli C and Wobrauschek P (2014). Comparison of two confocal micro-XRF spectrometers with different design aspects. X-ray Spectrometry, 43(2), pp.93-101.

60. Taylor, B., Bezuhly, M., Brace, M., Carter, M. and Hong, P. (2017). Effect of strontium citrate on bone consolidation during mandibular distraction osteogenesis. The Laryngoscope, 127(7), pp. 212-218.

61. Thurber, D.L., Kulp J.L., Hodge, H.C., Gast, P.W., and Wampler J.M. (1958). Science, 128: 256.

62. Tournis S, Economopolous D, and Lyritis GP (2006). Strontium Ranelate: A Novel Treatment In Postmenopausal Osteoporosis. Annals of the New York Academy of Sciences 1092.1: 403-407.

63. Weitkamp T, Haas D, Wegrzynek D, and Rack A. (2011). ANKAphase: software for single-distance phase retrieval from inline X-ray phase-contrast radiographs. Journal of Synchrotron Radiation, 18(4), 617-629.

64. Wohl, Gregory R. et al (2013). Accumulation Of Bone Strontium Measured By In Vivo XRF In Rats Supplemented With Strontium Citrate And Strontium Ranelate. Bone 52.1: 63-69.

65. Wright NC, Looker AC, Saag KG, Curtis JR, Delzell ES, Randall S, Dawson-Hughes B (2014) The recent prevalence of osteoporosis and low bone mass in the United States based on bone mineral density at the femoral neck or lumbar spine. J Bone Miner Res : Off J Am Soc Bone Miner Res 29:2520-2526

66. Wu, Yuchin et al. (2013) Compositional And Material Properties Of Rat Bone After Bisphosphonate And/Or Strontium Ranelate Drug Treatment. Journal of Pharmacy \& Pharmaceutical Sciences 16.1: 52-64.

67. Zamburlini M, Pejović-Milić, A. and Chettle D. (2008). Spectrometry methods for in vivo bone strontium measurements. X-ray Spectrometry, 37(1), pp.42-50.

68. Zamburlini, M. et al (2009). Strontium Depth Distribution In Human Bone Measured By Micro-PIXE. X-ray Spectrometry 38.4 271-277. 